\title{
Origin of Sex-Biased Mental Disorders: An Evolutionary Perspective
}

\author{
Rama S. Singh ${ }^{1}\left[\right.$ (D) Karun K. Singh $\mathrm{h}^{2,3} \cdot$ Shiva M. Singh ${ }^{4}$ \\ Received: 23 November 2020 / Accepted: 6 February 2021 / Published online: 25 February 2021 \\ (c) The Author(s) 2021
}

\begin{abstract}
Sexual dimorphism or sex bias in diseases and mental disorders have two biological causes: sexual selection and sex hormones. We review the role of sexual selection theory and bring together decades of molecular studies on the variation and evolution of sex-biased genes and provide a theoretical basis for the causes of sex bias in disease and health. We present a Sexual Selection-Sex Hormone theory and show that male-driven evolution, including sexual selection, leads to: (1) increased male vulnerability due to negative pleiotropic effects associated with male-driven sexual selection and evolution; (2) increased rates of male-driven mutations and epimutations in response to early fitness gains and at the cost of late fitness; and (3) enhanced female immunity due to antagonistic responses to mutations that are beneficial to males but harmful to females, reducing female vulnerability to diseases and increasing the thresholds for disorders such as autism. Female-driven evolution, such as reproduction-related fluctuation in female sex hormones in association with stress and social condition, has been shown to be associated with increased risk of certain mental disorders such as major depression disorder in women. Bodies have history, cells have memories. An evolutionary framework, such as the Sexual Selection-Sex Hormone theory, provides a historical perspective for understanding how the differences in the sex-biased diseases and mental disorders have evolved over time. It has the potential to direct the development of novel preventive and treatment strategies.
\end{abstract}

Keywords Sexual selection $\cdot$ Sex-biased diseases $\cdot$ Mental disorders $\cdot$ Male-driven mutation $\cdot$ Autism $\cdot$ Female immunity

\section{Abbreviations \\ CDGC Cross-Disorder Group of the Psychiatric Genom- ics Consortium \\ FASD Fetal Alcohol Spectrum Disorder}

Handling editor: Konstantinos Voskarides.

Rama S. Singh

singh@mcmaster.ca

1 Department of Biology, McMaster University, Hamilton, Canada

2 Stem Cell and Cancer Research Institute, McMaster University, Hamilton, Canada

3 Krembil Research Institute, University Health Network, Toronto, Canada

4 Department of Biology, University of Western Ontario, London, Canada

\section{Introduction}

Why does the prevalence of certain diseases differ in men (boys) and women (girls)? Being male is the single largest risk factor for early mortality in developed countries (Kruger and Nesse 2004). A 2008 World Health Organization survey investigating 36 diseases showed that, with a few exceptions (such as Alzheimer's disease and other dementias and iron deficiency anemia), men had higher mortality rates than women in almost all cases of non-sex-specific diseases. On reflection, differences in the prevalence and manifestation of various diseases between sexes are not surprising considering the differences between the sexes in terms of their sex chromosomes, development, anatomy, physiology, reproductive biology, and lifestyle.

Men and women differ in terms of presentation of sexspecific diseases, including prostate and testicular cancers for men and breast, cervical and ovarian cancers for women. However, the prevalence of some common diseases that are non-sex-specific also differs between men and women. Men generally show a higher prevalence of cardiovascular diseases (Albrektsen et al. 2016), whereas women show a higher prevalence of certain types of arthritis and rheumatic 
pains (van Vollenhoven 2009). A similar pattern is present for mental disorders, with a higher prevalence of anxiety and depression in women and a higher prevalence of antisocial disorders in men (Albert 2015). The causes of mental disorders are complex and remain unclear, although family, twin and population studies have indicated that both genetic and environmental factors are likely to play important roles in their development (Chokroborty et al. 2014). Such overarching and generalized explanations do not explain the known male bias associated with several mental disorders. Further, an insight into the sex-specific occurrence of these disorders may offer novel perspectives on their underlying causes and mechanisms, revealing potential avenues for understanding mechanisms and strategies for prevention and treatment. In this appraisal, we address the issue of sex-biased mental disorders using the example of autism, a common sex-biased mental disorder affecting children (Miles and Hillman 2000; Chakrabarti and Fombonne 2001) and present an evolutionary theory to explain sex-biased diseases and mental disorders in general.

\section{Theorizing Autism: What do we Know?}

Several theories have been offered to explain the male bias of autism. The "extreme male brain" theory proposes that the autistic brain represents an extreme form of the "typical male" brain profile (Baron-Cohen 2002). The "empathizing-systemizing discrepancy" cognitive domain metric shows sex differences: females are "empathizing," males are "systemizing", and autistic males and females are extremely "systemizing" (Baron-Cohen 2002). While excessive fetal testosterone was once thought to be a causal factor in autism, recent data implicate a multitude of steroid hormones (Baron-Cohen et al. 2020). According to this theory, one reason for sex differences may be that male autistic children are more likely to be diagnosed due to their extreme phenotypes.

Because females exhibit reduced autism risk, a genetic protective model has also been proposed which causes the diagnostic threshold to be higher for females than males but does not explain how or why (Lai et al. 2011; Robinson et al. 2013; Jacquemont et al. 2014; Gockley et al. 2015; Lai, Baron-Cohen et al. 2015a, b; Lai, Lombardo et al. 2015a, b; Werling 2016). Another theory proposes that sex differences in autism are associated with sex differences in grey and white matter (Torres et al. 2013; Gockley et al. 2015; Halladay et al. 2015). Substantial evidence suggests that males are more vulnerable than females beginning at conception, referred to as the fragile male hypothesis (Kraemer 2000). These theories confuse proximal and ultimate causes, i.e., causes that are immediate and of functional nature vs. causes that are evolutionary, respectively (Mayr 1961). These theories do not explain sexual disparities but instead offer potential proximal pathological causes for the high or low incidence of a disorder within a given sex. Therefore, it is logical to argue that the biological bases of sex differences in the brain are associated with development and involve differential gene expression patterns that cause the male brain to function and respond differently than the female brain (Trabzuni et al. 2013). More importantly, these sex differences are thought to result from evolutionary, ultimate causes. Evidence suggests that both genetic and epigenetic processes are inherently different for males and females and not only determine sex but also direct sexual differentiation, sexual selection, sexually antagonistic evolution and sexual dimorphism in both disease and health (Morrow 2015).

After summarizing a set of evolutionary principles with bearing on sex and gender as well as health and disease, we provide an overarching two-component theory involving sexual selection and sex hormones (SS-SH theory) to explain sex-biased differences in the prevalence of diseases and mental disorders. Using autism as an example, we show that, although the molecular mechanisms underlying diseases and mental disorders may be associated with individual risk factors or developmental anomalies, sex-mediated differences in their prevalence may be associated with the evolutionary history of sexual selection, which would affect all genes-both sex and non-sex. We propose that the malebiased prevalence of non-sex-specific mental disorders such as autism is the result of male-driven evolution leading to the following: (1) increased male vulnerability due to the negative pleiotropic effects of male-driven sexual selection and evolution for early gain of fitness; (2) increased rates of male-driven mutations and epimutations (germline and somatic) due to male-driven sexual selection and resulting in early fitness gains at the cost of late fitness; and (3) increased female immunity due to the development of antagonistic responses to mutations that are beneficial to males but harmful to females, reducing female vulnerability and increasing the thresholds for diseases and mental disorders. The SS-SH theory is presented here as a significant "first component" of the variation in sex-biased diseases and mental disorders.

\section{The Genetic Basis of Autism: An Overview}

The primary diagnostic features associated with autism include social deficits, language impairment and repetitive behaviors. These features are often associated with a variety of other abnormalities, especially neurological, including intellectual disabilities. Some authors (Constantino and Todd 2000) have suggested that most cases of autism are inherited and polygenetic, with small genetic effects contributing to the overall risk of disease manifestation. Others (Geschwind and Levitt 2007) have argued that autism exists in two forms: "complex" autism (20-30\%), which is defined by the presence of dysmorphology (minor physical anomalies) and is associated with a lower male-to-female ratio; 
and "essential" autism, which is defined by the absence of dysmorphology. Essential autism is common in males, has a high sibling recurrence risk and is associated with a family history of autism and autism-related disorders (Miles et al. 2005; Miles 2011). This form of autism is thought to be caused by common allelic variants that segregate in families, which would indicate the disorder's heritability and would account for families with multiple affected children (Klei et al. 2012; Gaugler et al. 2014). In fact, extensive genome-wide association studies have implicated hundreds of genes and a variety of associated genetic pathways in autism (Woodbury-Smith et al. 2018). A recent genomewide association study has shown tandem DNA repeats, both common and rare, to be significantly associated with Autism Spectrum Disorder (Trost et al. 2020). A more practical approach has been suggested (Fernandez and Sherer 2017) to divide Autism into clinically defined such as those caused by fragile $\mathrm{X}$ syndrome (4-5\%) and molecularly defined such as those based on genome-wide testing (20\%). The underlying cause(s) of the majority of the autism cases remains unknown.

In addition to common segregating variants, autism has also been associated with a host of de novo mutations (O'Roak et al. 2011; Gilman et al. 2011; Sanders et al. 2012; De Rubeis et al. 2014; Iossifov et al. 2014) and copy number variations (Sebat et al. 2007; Marshall et al. 2008; Pinto et al. 2010, 2014). Interestingly, the overwhelming proportion of de novo mutations have been shown to be paternal in origin and are associated with paternal age (O'Roak et al. 2011). Furthermore, a significant number of de novo events have been found to be recurring, affecting neuronal gene products (O'Roak et al. 2012). The identification of de novo mutations suggests the potential involvement of major disruptive (missense or nonsense) mutations that affect brainexpressed genes (Sanders et al. 2012). Although such mutations account for only $40 \%$ of de novo mutations, they have been shown to affect high-connectivity protein genes. These results suggest that recurring protein-altering mutations in highly connected brain-expressed genes may represent candidate causative mutations associated with at least some autism cases (Neale et al. 2012; Samocha et al. 2014).

More recent research exploring the causes of autism has focussed on epigenetic mechanisms, particularly DNA methylation (Nardone et al. 2014; Lad-Acosta 2015; Loke et al. 2015, Tremblay and Jiang 2019). Epigenetic changes have the potential to affect gene expression in response to environmental effects-including during neurodevelopmentwithout altering the gene sequence (Feng et al. 2007). Genes associated with the epigenetic pathway, which have been identified through a variety of approaches, constitute a sizable proportion of candidate autism genes, and are included in the autism database (http://gene.sfari.org/). Even at this relatively early stage of epigenetic research, a small number of replicated methylation differences have also been associated with autism (Ladd-Acosta et. al 2014; Nardone et al. 2014). These results support the potential contribution of epigenetic processes to the etiology of autism. The involvement of epigenetic changes, particularly DNA methylation, is also relevant in the context of sex differences. DNA methylation, which is known to differ between the two sexes, appears early, and affects imprinted genes and X-inactivation (Skuse 2005). More importantly, an individual's sex has the potential to determine DNA methylation-based, sex-specific gene expression at any stage of development and differentiation, including during neurodevelopment. Epigenetic differences may also affect paternal sperm, which has the potential to contribute to the development of autism in offspring (Feinberg et al. 2015).

In summary, several major breakthroughs related to the genetic determinants of autism have been reported, including the identification of many common alleles (single-nucleotide variations and copy number variations) that currently segregate within the population; prezygotic and postzygotic de novo mutations (single-nucleotide variants and copy number variations); and epigenetic changes that impact gene expression (DNA methylation and histone modification). Ultimately, these determinants can cause imbalances in highly regulated neurodevelopmental processes that manifest as variations in disease prevalence and manifestation. The results of published studies argue that autism, like most mental disorders, is genetically heterogeneous, involving many genes that are implicated in a variety of pathways that affect neurodevelopment and brain function. Furthermore, these genes may be altered by a variety of mutational and epimutational mechanisms, as supported by the extensive variability in the manifestations of autism.

\section{The Sex-Biased Prevalence of Autism}

Both the prevalence and the severity of manifestation of autism differs in boys and girls; recently, an increasing number of studies have begun to explore the low prevalence of autism in females (Lai et al. 2011; Lai et al. 2015a, b). Overall, the reported male-to-female ratio among individuals with autism ranges from 4:1 (Chakrabarti and Fombonne 2001) to 2-3:1 based on recent combined data (Lai et al. 2013; Lai et al. 2015a, b). Individuals with essential autism are more likely to be male (6.5:1) (Miles 2011), with some earlier studies reporting disparities as high as 23:1 (Hillman et al. 2000). However, a recent meta-analytical review showed a ratio of 3:1 (Loomes and Mandy 2017). Autistic girls tend to be diagnosed later than autistic boys and tend to have more severe symptoms (Shattuck et al. 2009; Giarelli et al. 2010; Begeer et al. 2013). However, the differences are not straightforwardly dictated by sex biology and are 
interwoven with the patient in the context of sex and gender (Lai and Szatmari 2020

The reduced incidence and increased severity of autism in females may be attributable to many factors. First, sexlimited factors may be involved, such as the sex-determining region Y (SRY) gene, $X$-inactivation, sex-limited genomic imprinting, Y-linked inheritance and unique $\mathrm{X}-\mathrm{Y}$ interactions (Beaudet 2017). Second, the levels of gene expression in different brain regions may differ in males compared to females (psychENCODE 2015; Hu et al. 2015). In addition, female genotypes may be developmentally protective (Werling and Geschwind 2015) and may require higher thresholds for mutations or gene expression to manifest the same levels of severity (Gockley et al. 2015; Lai et al. 2015a, b; Robinson et al. 2015). Third, male fetuses may be more susceptible to developmental and environmental factors (Hu et al. 2015; Werling and Geschwind 2015). Fourth, males and females may differ in various etiological aspects; for example, female autism may represent a more complex type of autism caused by multiple factors (Geschwind and Levitt 2007). Finally, the male-biased prevalence may not be unique to autism, and sex differences in the susceptibility of normal neurodevelopmental processes to environmental perturbations, rapid neonatal brain growth and incomplete neurodevelopment may result in additive effects on disease prevalence in general (Table 1). However, one thing appears to be for sure: the higher levels of sex bias in essential autism as compared to those caused by de-novo mutations make sense as segregating genes causing essential autism would have had more time to evolve sex-biased differences.

Table 1 Male-driven processes producing male-biased evolutionary changes in the genome

Male-determining genes

Male-driven increased rates of mutation

Male-biased somatic mutations and epimutations

Male-driven purging of deleterious mutations

Sex-limited genomic imprinting

Male-biased increases in gene expression ranges

Male-biased rates of sequence evolution

Male-specific transcripts, new genes, and loss and gain of function

Male susceptibility to gestational perturbations

Male susceptibility to environmental stresses

Male brain plasticity

Male-driven evolution of senescence

Mate choice and the evolution of menopause

Male-driven persistence of maternal mortality
In combination with other genes expressed later in life, SRY - the male-specific, sex-determining gene - sets the stage for lifelong hormonal effects on sexual and non-sexual traits (Gubbay et al. 1990; Sinclair et al. 1990; Raymond et al. 1998; Bourc'his and Bestor 2006; Arnold 2017)

Mutation rates are male-biased, with mutations occurring at higher frequencies in males than females and are higher than be explained by number of germ cell divisions (Miyata et al. 1987; Drost and Lee 1995; Ellegren and Fridolfsson 1997; Hurst and Ellegren 1998; Ellegren 2007; Keightley 2012; Lynch 2016)

Cell type specific somatic mutations are a new addition to the measures of genetic differences ( Milholland et al. 2017) and they play a critical role in sex-specific oncogenesis (LopesRamos et al. 2020). A pan-cancer analysis showed that $15 \%$ of the genes mutated in tumors had sex biased somatic mutations that are more prevalent in male tumors (Li et al. 2018). Sex biased epigenetic changes, particularly DNA methylation are known to exist across different tissues including the brain (Xu et al. 2014)

Sexual selection through male-male competition would lead to the elimination of deleterious mutations not only in sexual traits but in the whole genome (Whitlock and Agrawal 2009)

Male imprints are established early in life and persist longer, resulting in highly sexually dimorphic imprinted gene expression (Bourc'his and Bestor 2006)

Male-biased genes show larger ranges of gene expression levels in Drosophila (Ranz et al. 2003; Meiklejohn et al. 2003; Parisi et al. 2004; Zhang et al. 2007)

Male-biased genes show higher rates of sequence evolution (Torgerson et al. 2002; Lawniczak and Begun, 2004; Zhang et al. 2004; Khaitovich et al. 2006; Pröschel et al. 2006; Haerty et al. 2007)

Males generally express more genes and proteins, such as the accessory gland proteins of Drosophila, for male-specific functions (Wolfner et al. 1997)

Males are more sensitive than females to adverse gestational conditions and the impact can last lifetime (Navara 2014)

Males are more susceptible than females to environmental variations throughout their lives (Bale 2009; Beaudet 2017)

Males are more susceptible than females to perturbation in gene expression associated with synaptic plasticity, possibly due to gene-environment interactions (Andersen and Teicher 2008; Lai et al. 2013; Mottron et al. 2015)

Male-male competition for early gains in reproduction may accelerate the accumulation of deleterious mutations that affect senescence (Williams 1957; Kirkwood and Rose 1991)

A male preference for younger mates would lead to the accumulation of female infertilitycausing genes and the evolution of menopause (Morton et al. 2013; Takahashi et al. 2017; Chan et al. 2020)

Child marriage and repeated marriage including serial monogamy exacerbate the problem of maternal mortality making it persist longer (Jagadeeshan et al. 2019 


\section{Evolutionary Principles in Relation to Sex and Gender in Disease and Health}

Sexual selection is a significant force of evolution and sexual dimorphism. The evolutionary framework presented here for the evolution of sex-biased diseases and mental disorders primarily refers to the sex biases associated with the prevalence, rather than the causes, of diseases. In this section, we summarize a set of evolutionary principles in relation to the evolution of sexual dimorphism in disease and health and follow it by laying out a comprehensive theory to explain sex-biased differences in diseases and mental disorders. These evolutionary principles are based on evidence obtained from non-human, model organisms such as fruit flies. We acknowledge that extrapolation from a small number of non-human species to humans based on putative evolutionary principles is not necessarily completely reliable, especially with respect to higherresolution details of mechanism or outcome.

\section{From Sexual Selection to Male- and Female-Driven Evolution}

In the Descent of Man and Selection in Relation to Sex, Darwin (1871) noted that as organisms' sensory functions developed over time, so did their exercise of mate choice during mating and reproduction. Among higher organisms, Darwin (1871) hypothesized that sexual selection was often more important than natural selection. Despite his awareness of males' often aggressive behavior during the initiation of mating through song, dance, and the pursuit of females, in his theory of sexual selection Darwin mainly focussed on male-male competition and female choice in relation to mate choice. A large body of data has been gathered on male behavior, both generally and during mating, and in light of which it has become clear that role of sexes in relation to each other involves more than mate choice (sexual selection) and should be extended to all aspects of mating behavior associated with reproduction (Markow 2002; Singh and Jagadeeshan 2018). For example, males engage in mate search, defending territory, male-male competition, courting, nuptial gifts, mating, mate guarding and sperm competition. Similarly, females engage in mate selection with respect to mate quality, multiple mating, and mate retention. We have introduced the terms "male-driven evolution" and "female-driven evolution" to capture the extended meaning of sexual selection (Singh and Kulathinal 2005; Jagadeeshan et al. 2015). We are aware that, strictly speaking, some of the behaviors listed here are outside canonical sexual selection; however, our goal is not to redefine sexual selection but to extend it. We need a term that includes all aspects of mate-driven behaviors associated with mating, and we feel that male-driven and female-driven evolution describe the sexes' roles and impacts on each other's fitness better than canonical sexual selection (Bateman 1948; Singh and Jagadeeshan 2018). Male-female-driven evolution is especially relevant to human evolution as the sexes have become the most important part of each other's lifestyle, environment, and ecology. Sexes drive each other.

\section{Male-Driven Evolution and the "Masculinization" of the Genome}

Sex-biased developmental processes are the results of the evolutionary integration of millions of years of small modifications that have accrued differentially in males and females (Singh and Jagadeeshan 2018). For example, although the concept of equal biparental genetic material (autosome) contributions (barring mitochondria and $\mathrm{Y}$ ) is simple to understand, parental imprinting can be difficult to explain without understanding the theory of sexual antagonism (Arnqvist and Rowe 2005; Bedhomme et al. 2008) and the associated complementation of paternal and maternal genomes involving specific sets of imprinted genes under evolutionary pressure (Kaneko-Ishino et al. 2006). These mechanisms ensure cross-fertilization and the maintenance of genetic variation in populations.

The various sexually dimorphic molecular mechanisms associated with male-biased changes are summarized in Table 1. Starting with the sex-determining gene (SRY), a battery of differently expressed genes is sequentially activated, resulting in sex-based differences in morphology, physiology and behaviors that involve sex-specific, sex-limited, and sometimes non-sex-specific genes. Gene expression studies in Drosophila have demonstrated that over $50 \%$ of all genes are expressed in a sex-biased manner (Haerty et al. 2007). Males have higher levels of sexbiased gene expression, and male-biased genes display (1) a wider range of gene expression levels, (2) an increased number of male-specific transcripts or unique transcripts and (3) increased rates of molecular evolution resulting from higher DNA mutation rates and/or stronger selection pressures (Haerty et al. 2007; Assis et al. 2012). In Drosophila and mice, sperm genes have been shown to evolve faster than other genes with respect to both sequence and coding length.

While males and females may share the same genes, their gene expression patterns (Kang et al. 2011; psychENCODE 2015) and interaction networks (Sousa et al. 2017) can differ significantly due to sex-limited expression (Bedhomme et al. 2008), genomic imprinting (Reik and Walter 2001) and the translocation of genes on the X chromosome (Rice 1994). Parsch and Ellegren (2013) showed sex-biased expression can accelerate the evolution of sex-linked genes. Lemos et al 
(2010) showed the role of Y chromosome of Drosophila as a major source of epigenetic variation in natural populations that can modulate the expression of biologically relevant phenotypic variation. In humans, Xue et al. (2014) examined sex-biased gene expression in the prefrontal cortex and found the largest fraction of sex-biased genes expressed outside gonadal tissues.

These sex differences likely come from male-driven evolution (Singh and Kulathinal 2005). The male sex drive intensifies male-male competition for sex (Anderson 1994), and only a small percentage of males may be allowed to mate. The male sex drive is stronger and self-enforcing, inducing the rapid evolution of sex-related fitness traits over time, which can generate cascading pleiotropic effects between the sexes.

\section{Higher Rates of Male-Biased Mutations and Sexual Dimorphism in Disease and Health}

Most estimates of the germline mutation rate show a male bias (Wilson-Sayres and Makova 2011). Often, they are based on the frequency of population-wide autosomal dominant diseases that result from new mutations in one parental gamete and represent the direct observation of mutations in genes and genomes in parents and their offspring. Over the years, these diseases-including endocrine neoplasia type 2A (MEN2A) (Carlson et al. 1994), Apert syndrome (Moloney et al. 1996) and Noonan syndrome (Tartaglia et al. 2010) - have been recognized as showing predominantly paternal origins. Today, a direct estimate of the mutation rate is being generated using gene and genome sequences. The 1000 Genomes Project identified a de novo mutation rate ranging from $1.0 \times 10^{-8}$ to $1.4 \times 10^{-8}$, with an average of $\mu=1.1 \times 10^{-8}$ (Genomes Project Consortium 2012). A more recent assessment based on whole-genome sequencing performed in 78 trios from Iceland found a mutation rate of $\mu=1.20 \times 10^{-8}$ (Besenbacher et al. 2015). These results imply that, on average, as many as 100 de novo mutations arise in a newborn, with a net fitness loss of about $1 \%$. Many diseases often exhibit a paternal age effect (i.e. an association with the age of the father at the time of the affected child's birth), and it is expected that a large proportion of de novo mutations come from the father. Male mutation rates increase twofold between the ages of 20 and 40 and at a much higher rate thereafter (Crow 1997). Germline mutations become part of the genetic architecture of the population, and their impacts are realized due to their expression in time and space, which may be sex-specific (Rigby and Kulathinal 2015), particularly among genes expressed in the brain (Trabzuni et al. 2013). Stanley and Kulathinal (2016) showed that neurogenic genes were on average longer in size than non-neurogenic genes in coding regions, untranslated regions, and miRNA and transcription factor binding sites.
Longer neurogenic genes would provide a larger mutational target for behavioral change.

These results provide a foundation for the existence of a differential genetic threshold necessary for the manifestation of deleterious mutations between the two sexes. Based on different gene numbers (due to $\mathrm{X}$ and $\mathrm{Y}$ ), expressions and sex-specific thresholds, a given set of disease-causing mutations may be sufficient to manifest a disorder in one sex but not the other. Additionally, a deleterious mutation may manifest mildly and early during development in only one sex. This is likely to be the case for gene mutations associated with essential autism, which represents a milder form of the disorder and is much more frequently identified in males. Conversely, an identical genomic combination present in a female may generate a different physiological threshold due to female-specific expression. The female-specific threshold may thus not be sufficient for the manifestation of the disorder, which would allow females to be more tolerant of and protected against deleterious mutations (Cauvet et al. 2019). More importantly, any manifestations of the disorder in females may require more severe mutations, including major deletions and duplications. These mutations may affect the developmental dysmorphologies common in "complex" autism, which occurs more frequently in females. We suggest that this interactive model is under constant pressure due to differential mutations in the parental germline and the developing brain, sex-specific epigenetic regulatory mechanisms, and the realization of sex-specific metabolomics (the threshold for disease manifestation).

\section{Male-Driven Evolution and Female Fitness Modification}

To the extent that males and females have different lifestyles, they can affect each other's survival and reproductive success. Male mating behavior has one of the most unexpected and consequential effects on women's health, namely affecting women's fertility and longevity. We demonstrate this with respect to the origins of menopause and post-menopausal longevity. There is a tendency for men to prefer to mate with younger women in all cultures and this shows up in the age differences of the couples. United Nations population surveys show that as late as 2014 , average age of men at first time marriage is $2-5$ years higher than that of women (United Nations Population Facts 2016). Age differences are higher is developing countries which suggests the age difference must have been larger in the past. History shows that through polygamy, serial monogamy, harems and brothels, men have maintained a preference for younger women. From an evolutionary point of view, all else being equal, early reproduction pays off; however, the preference for younger women has produced a major maladaptive effect in women, ultimately resulting in the 
loss of reproductive ability after menopause. The preference for younger women means depriving older women of the opportunity to reproduce, which could have led to the accumulation of female infertility mutations giving rise to menopause (Morton et al. 2013; Takahashi et al. 2017; Chan et al. 2020). A correlated negative response to this male mating behavior has been the persistence of maternal mortality due to repeated cycles of "younger mates-maternal mortality-serial monogamy-younger mate" (Jagadeeshan et al. 2019). Male-driven mate choice through older males mating with younger females promotes longevity in both sexes, as older, long-living males contribute their genes to both their sons and daughters (Tuljapurkar et al. 2007), thus solving one of evolutionary biology's paradoxes, namely why women live beyond menopause (Hamilton 1966). The evolution of menopause is a major factor in women's health. While male-driven evolution causes a major loss of female fitness via menopause, its effects on female immunity is supposed to be increased via antagonistic evolution.

\section{Male-Driven and Male-Benefiting Mutations, Antagonistic Evolution, and Female Immunity}

While the role of male-driven sexual selection in the evolution of senescence is well known (Williams 1957; Kirkwood and Rose 1991), the role of male-driven, male-benefiting mutations that are harmful to female in promoting female immunity through antagonistic evolution has only relatively recently been investigated and is consequential to women's health (Arnqvist and Rowe 2005; Bedhomme et al. 2008). The discovery of higher rates of male-biased mutations has added to the importance of male-driven antagonistic evolution in females. The combined effects of the evolution of senescence through male-male competition for early fitness gains (Williams 1957; Kirkwood and Rose 1991) and females' antagonistic responses to protect themselves from the deleterious effects of male-benefiting mutations (Arnqvist and Rowe 2005; Bedhomme et al. 2008) can lead to differential rates of senescence as well as higher thresholds for diseases and mental disorders in females (Morrow 2015). This higher level of inherent immunity underlies the generally lower prevalence of diseases in women. In addition, compared to men, women generally exhibit fewer healthaffecting conditions as they age.

\section{Rapid Evolution and the Complexity of the Genome: The Runaway Brain}

Mental disorders are generally complex and present with varying symptoms due to several contributing factors. First, the brain is a complex structure, and the various regions of the brain likely overlap in structure and function; therefore, the neurons that affect a given behavior can be found throughout the brain (Sofroniew 2017). Second, brain functions such as communication require the engagement of multiple cognitive centers-such as those responsible for memory, reason, logic, and emotion-and the simultaneous interconnection of multiple brain function centers may result in long-term coordinated evolution and interdependence. Third, as proposed by King and Wilson (1975), the rapid evolution of the brain supposedly takes place through regulatory gene evolution (Chen et al. 2018). Fourth, as is the case for any trait under strong selection pressure and rapid evolution, multi-region brain interactions are likely to be affected by population genetic constraints imposed by factors besides genetic variation, such as genetic linkage, selective sweep, background selection, drift-driven fixation of deleterious mutations, pleiotropy, and the evolution of complex and shared functions (Guan et al. 2019). Finally, because of the wider tissue distribution of brain genes, brainaffecting mutations would be expected to hit a larger target of traits than other mutations. Brain tissue-expressed genes in humans have been shown to be of larger size on average, thus providing a larger mutational target (Stanley and Kulathinal 2016). Several mental disorders, such as attention deficit hyperactivity disorder, major depressive disorder, schizophrenia, and bipolar disorder, have been shown to be affected by common neurotransmitters, including serotonin, dopamine, norepinephrine, and glutamate systems (CDGC: Cross-Disorder Group of the Psychiatric Genomics Consortium 2013). Consequently, a single neurotransmitter may have multiple effects associated with various mental disorders.

Neurodevelopment is complicated and involves several unusual features. Unlike other organs, the brain is characterized by long periods of development, differentiation, pruning and maturity. Neurodevelopment starts early in organismal development and can continue for decades in humans. This developmental continuum is highly sensitive to environmental effects, and even single exposures to adverse environments can leave lifelong imprints. For example, prenatal alcohol exposure is the primary cause of fetal alcohol spectrum disorder (FASD), a common developmental disorder characterized by lifelong behavioral abnormalities, including learning and memory deficits (Chokroborty-Hoque et al. 2014). Also, neurodevelopment involves unusual postzygotic somatic mutations which may involve a variety of mutational mechanisms, including transpositions (Krupp et al. 2017; Lim et al. 2017) and rare copy number variants (Wilfert et al. 2017). These mutations appear de novo during ontogeny, play an important role in neuronal differentiation and result in every brain's representing a genetically unique mosaic. Postzygotic mutations constitute a significant proportion of de novo mutations and may contribute to the liability threshold of developing brain disorders (Singh, Castellani and Hill 2020). How the contributions of individual-specific 
de novo mutational events contribute to neurodevelopment remain unclear, as does whether these events occur similarly or differently in male and female brains. If sex-specific differences in somatic mutations occur, as with germline mutations, these mutational events may contribute to the increased incidence of autism in males, adding yet another source of sex-related differences that can affect individual brain function. The increased mutation rate observed in males compared to females may cause higher genomic heterogeneity through spermatogenesis, which is transmitted to both sexes and expressed differently in each, as well as somatic de novo mutations during neurodevelopment, which may preferentially affect males. In both cases, these mutations are sources of novel variations and the generation of extreme phenotypes associated with a unique gamete and a unique mosaic brain.

A recent study (Shi et al. 2016) performed a time series analysis of genome-wide transcription profiles from human brains at major developmental stages (prenatal, early childhood, puberty and adulthood) and showed that more than 2000 genes exhibited between-sex divergences during major developmental stages, with the greatest number found at puberty (4164 genes). More importantly, the male-biased genes were found to be highly enriched "for genes involved in neurological and psychiatric disorders like schizophrenia, bipolar disorder, and autism, while no such pattern was seen for the female-biased genes" (Shi et al. 2016). Such results directly support the theory that male-driven mutations and gene expression have the potential to represent a major source of sex bias in some mental disorders.

The rapid evolution of the brain increases the likelihood that brain-expressed genes display shared functions and pleiotropic effects. Some evidence supports male-biased increases in physical growth (de Zegher et al. 1999) with respect to birth length, weight and head circumference (Reuter et al. 2018), which may cause male-biased birth complications and could potentially affect neuronal development. A faster fetal growth rate may also increase vulnerability to developmental perturbations with pleiotropic effects on mental capacity genes and behavioral faculties in a sexbiased manner.

\section{The Theory}

Sexual dimorphism is prevalent across mammalian species (Karp et al. 2017) and it occurs in many human complex traits including diseases and mental disorders (Rawlik et al. 2016). Barring the effects of lifestyle and work-related causes, sex bias in diseases and mental disorders can be attributed to two main biological causes: male-driven evolution and female sex hormones (Fig. 1). The former is the result of male-male competition for fitness gains and the

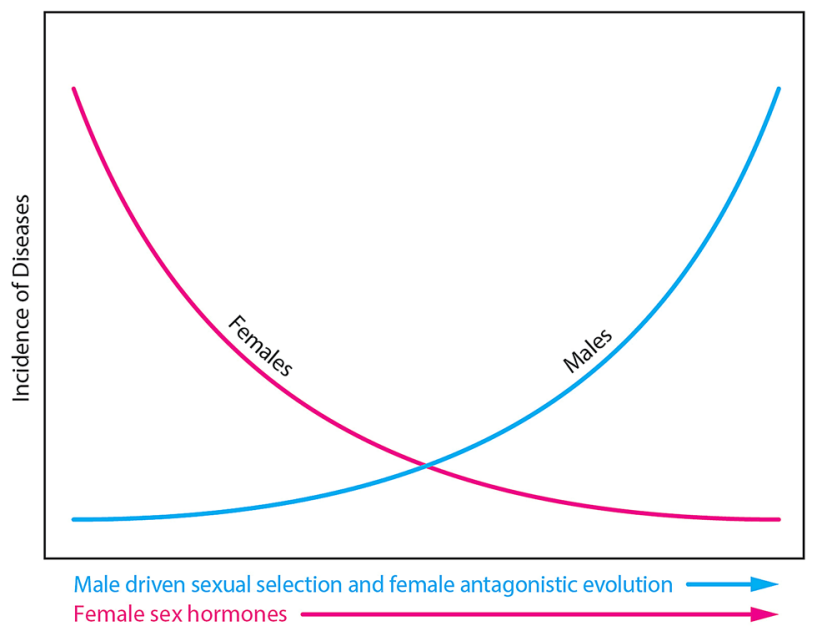

Fig. 1 Role of male-driven sexual selection and female sexual hormones in the incidence of sex-biased diseases and mental disorders under the Sexual Selection-Sex Hormone Theory (see text for explanation)

evolution of male-benefiting and female-harmful mutations leading to the antagonistic evolution of female protection. A hypothetical example of male-benefiting mutation or trait that is harmful to females can go like this: Male sexual desire during pregnancy would be risky to the fetus, and it would be better for women to evolve low sexual desire and/or higher rejection during pregnancy. Sex hormones have been shown to provide female protection (Abel et al. 2010). This is sensible from an evolutionary perspective, as females are more important than males for population fitness. Sex hormone fluctuation during reproductive years has been shown to increase female vulnerability to diseases such as migraine (Artero-Morales et al. 2018) and depression (Brummelte and Galea 2016; Slavich and Sacher 2019) and is highly sensitive to environmental and social conditions. As a result, it can be expected to vary across communities and countries (Slavich and Sacher 2019). Health is complicated; but other factors must be involved. Sexual Selection-Sex Hormone hypothesis predicts that due to the combination of the two factors, females will show greater resistance to physiological disruption or dysfunction due to mutation or epimutation. Furthermore, the theory predicts that female-biased ratios be higher for sex hormone-affected diseases and disorders.

The processes and outcomes of male-driven evolution are depicted in Fig. 2, while Fig. 3 shows how it leads to the evolution of male vulnerability and female immunity. Maledriven evolution-sex hormone theory posits the following: (1) due to the stronger male sex drive, male-male competition for mates and the opportunity for repeated mating in continuously breeding populations, male-driven selection pressure is stronger and perpetual; (2) male-driven selection 
Fig. 2 Male-driven and Femaledriven sexual selection and their effects on sexual dimorphisms in morphology, physiology, gene expression, and life history traits

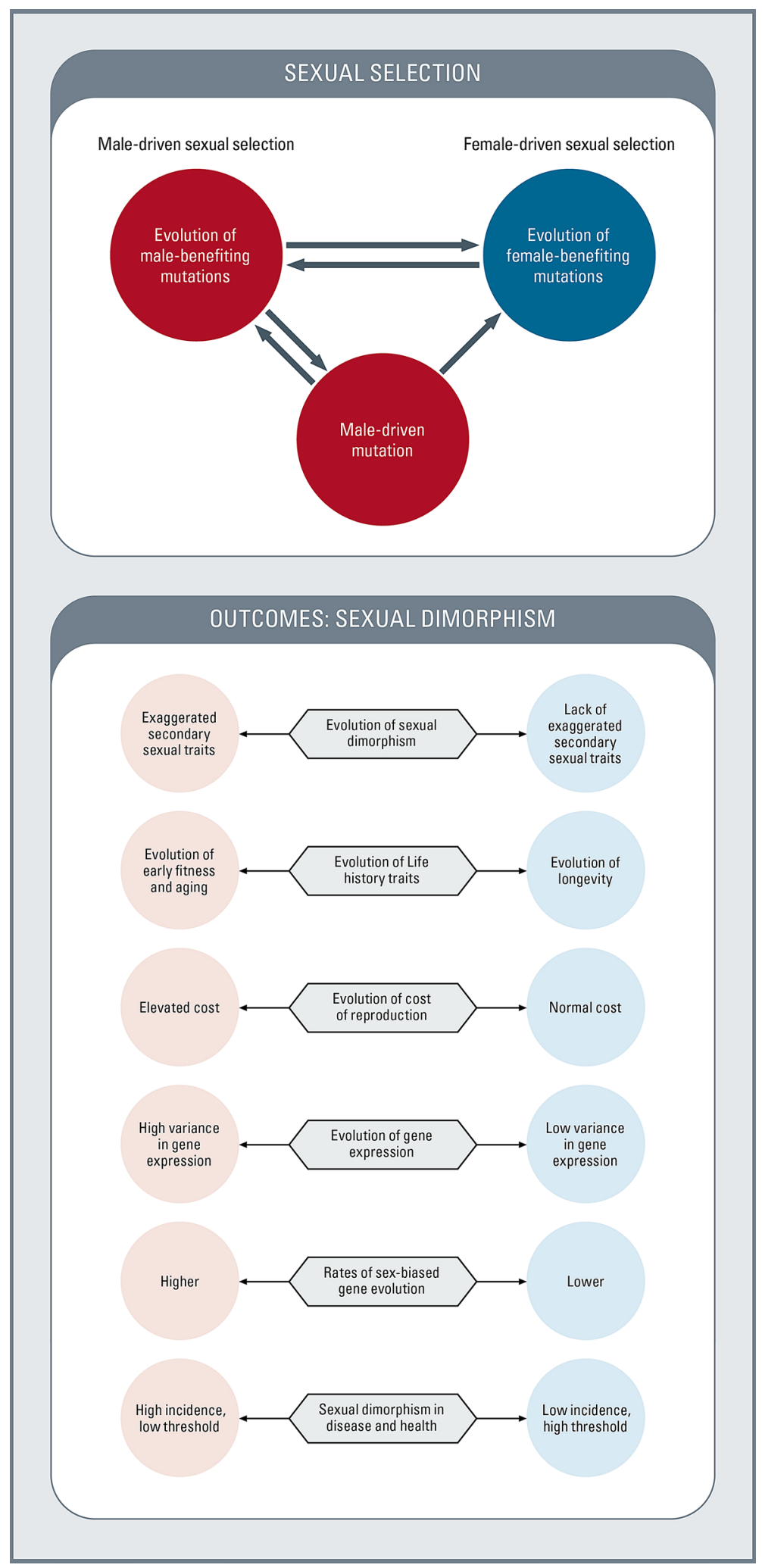

pressure, in combination with higher rates of male-driven mutation, has powerful effects on evolutionary changes in both general and male-biased traits; (3) rapid sexual selection-driven changes in combination with male lifestyles favoring early fitness gains foster the accumulation of lateacting deleterious mutations, with pleiotropic health effects and a general loss of fitness in later life; and (4) sexual selection-driven changes in gene expression that are beneficial 


\section{Male Driven Evolution}

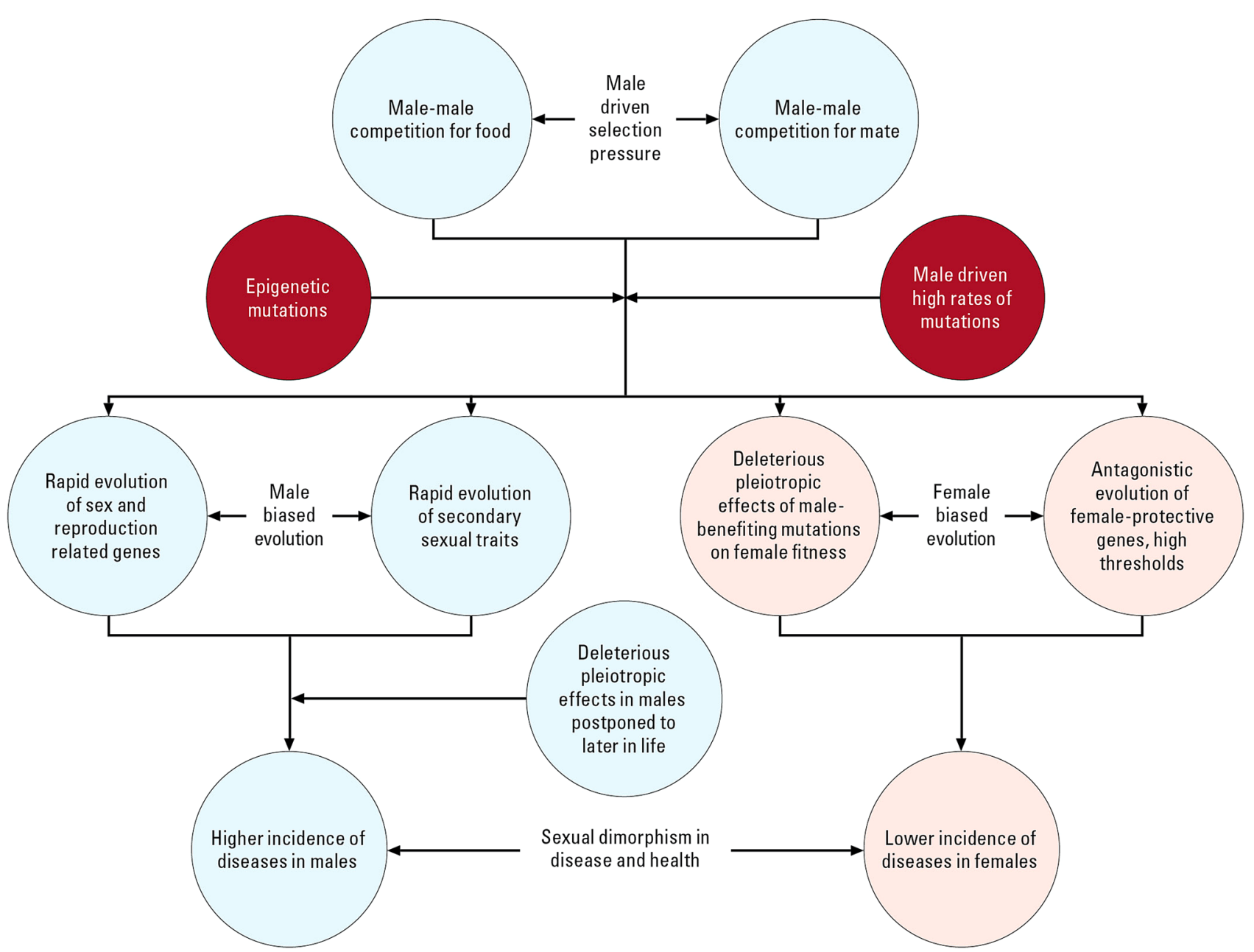

Fig. 3 Schematic representation of male-driven and female-driven evolutionary mechanisms, sexual antagonism, and sexual dimorphisms in disease and health

to males but harmful to females place additional pressure on females to respond through antagonistic evolution, giving rise to higher female immunity and higher thresholds for exhibiting disease symptoms (Arnquist and Rowe 2005).

The combined effect of the Sexual Selection-Sex Hormone theory is demonstrated in the three examples shown in Fig. 4. This graph is meant to serve as a general illustration. The three examples of mental disorders were chosen to show the effect of male-driven sexual selection in the case of autism, sex hormone in the case of major depression disorder, and possibly both in the case of schizophrenia. The hypothesis presented here can explain the sex-biased patterns of these disorders but remains to be experimentally investigated. The lifetime incidence of schizophrenia in men and women is not very different; the incidence is higher among men aged 15-30 and moderately higher in women aged 45-60 (Abel et al. 2010). It is likely to be more complicated (Li et al. 2017) but the underlying causes of schizophrenia may be sex-specific modulators, as women have been shown to suffer less than men from cognitive deficits (Goldstein et al. 1998).

The reduced sex disparity in de novo mutation-cased autism may be the result of evolution. According to the hypothesis outlined above, sex bias is the result of evolution, not simply of mutation \& variation. Male-driven germline variants get inherited by both sexes but have not had the time to go through sex-biased evolutionary modifications. Unlike segregating common variants associated with essential autism, rare de novo mutations of large effect (associated with complex autism) may face sperm competition including 

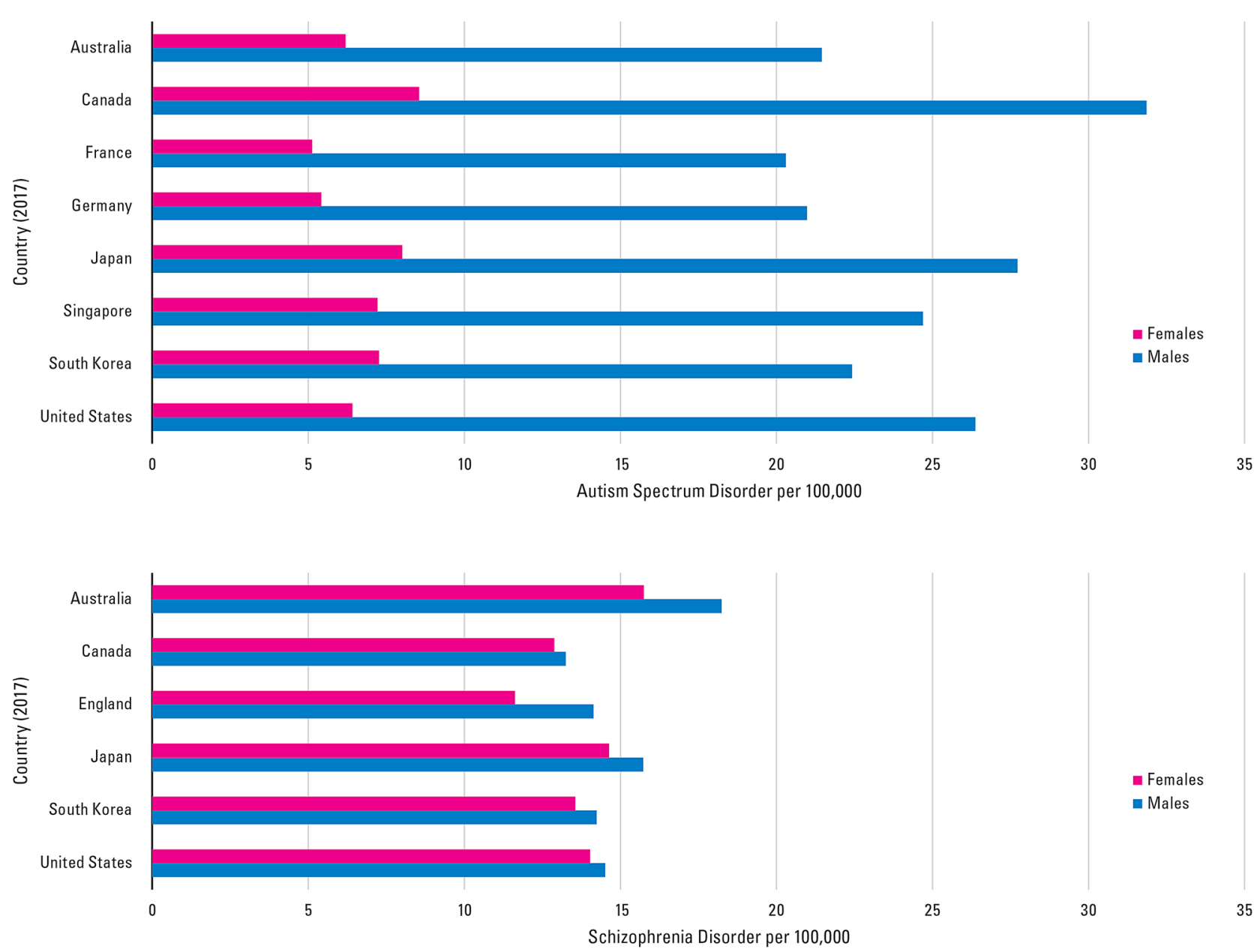

Females
Males

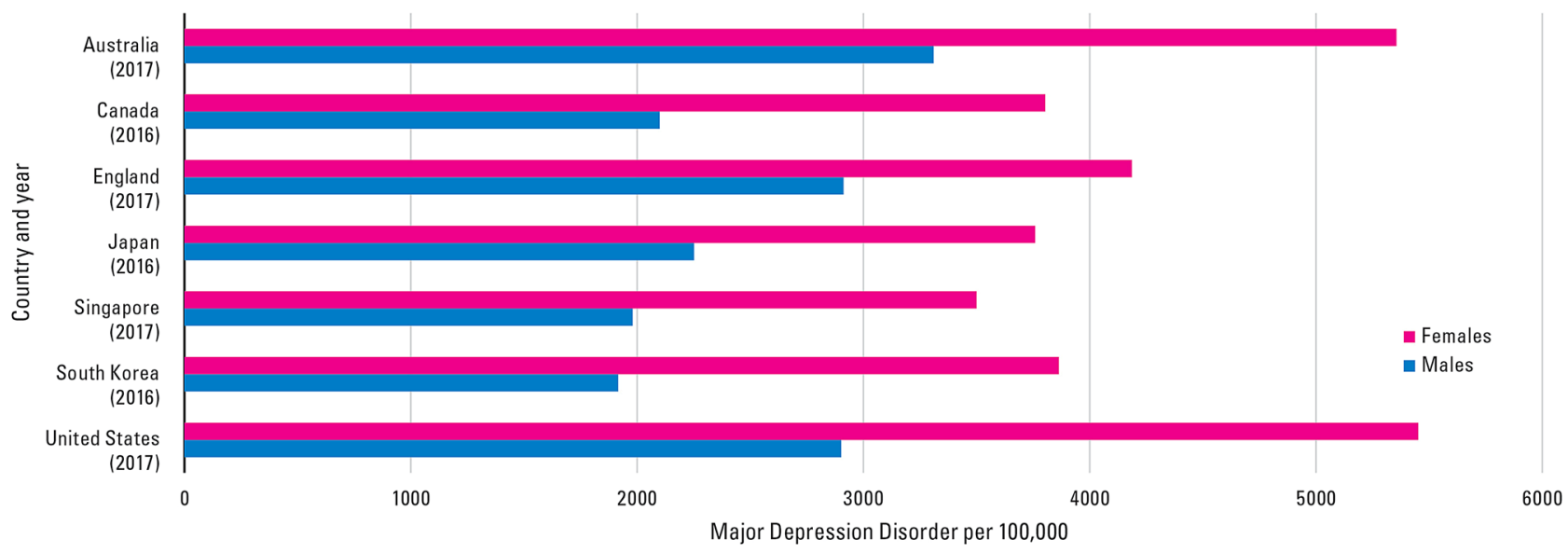

Fig. 4 Estimated age-standardized incidence rates of autism, schizophrenia, and major depression in both sexes, all ages

lethality in early embryonic and/or fetal development. We may add that abortuses are known to carry increasing number of large effect mutations and are sex biased (higher for males) as there is no data to reliably reflect on their direct involvement in autism.

\section{Supporting Evidence}

Male-driven evolution and sexually antagonistic evolution are major forces of sexual divergence (Figs. 2 and 3). Almost everything we know about sex-biased diseases can 
be explained by this evolutionary hypothesis. It is, however, important to point out that since the hypothesis being presented here straddles between two different disciplines- evolutionary biology and Medical sciences, stronger test of the hypothesis will come from new testable predictions and new observations. In the following subsections, we summarize available evidence and make predictions that would support the hypothesis.

\section{Male Bias in Autism is Greater for "Essential" and Less Severe Autism Cases}

Several key observations regarding the nature of sex differences in autism support the male drive theory (Chakrabarti and Fombonne 2001; Miles 2011). This theory predicts that a significant proportion of autism cases may be caused by mutations in large numbers of non-pathological genes, which appears to be the case (Constantino and Todd 2000). The theory also predicts that the genes involved will likely be longer, interact with other genes and be associated with extensive pleiotropic effects. Furthermore, these genes may differ in number and be differentially expressed in the two sexes, with the potential to offer a lower threshold for the highly variable manifestation of the essential (less severe) form of autism in males.

\section{Females Show Fewer Cases of Diagnosed Autism but More Severe Symptoms}

This is expected based on the theory of antagonistic evolution. If the severe male bias observed for essential (less severe) autism is due to the pleiotropic effects of maledriven minor or multifactorial mutations, females would be expected to be selected for protection against these mutations through sexually antagonistic evolution. Conversely, major mutations - de novo or otherwise-would affect both sexes equally. The lower incidence of autism in girls may result from female-favoring protection mechanisms due to sexual antagonism effects (Rice and Chippindale 2001; Bedhomme et al. 2008). Male bias appears to be more pronounced for less severe forms of autism, which would be expected according to the theory of mutation-selection balance. We would expect that milder autism, which results from gene mutations that segregate in the population, would be moderated by antagonistic effects in females and exhibit greater male bias than severe autism. Women differ from men in immune response and show higher levels of circulating antibodies and greater cytokine production in response to infection. The higher immunity of females as compared to males is phylogenetically conserved suggesting adaptive advantage in reproductive success (Klein and Flanagan 2016; Fink and Klein 2018).

\section{The Effects of Male-Biased vs. Female-Biased Disease-Causing Genes and Alleles are Expected to be Negatively Correlated}

This follows directly from antagonistic selection theory. If male-biased diseases are the pleiotropic effect of malebenefiting mutations, such mutations will be suppressed in females, giving rise to allele-specific immunity. In a recent study, Kamitaki et al. (2020) demonstrated the role of sex differences in complement protein levels in producing sexual dimorphism in diseases, i.e., a negative correlation between the effects of $\mathrm{C} 4$ alleles in men and women (on schizophrenia in men and on systemic lupus erythematosus [SLE] and Sjogren's syndrome in women). This appears to fit the models of intra-locus sexual conflict resolution (Bedhomme et al. 2008). While we expect that more such genes will be found, sexually dimorphic disease genes need not all be allelic; the majority arise from intergenic resolutions of sexual conflicts (Parker and Patridge 1998).

\section{Epigenetic Responses to Environmental Challenges are more Likely to Occur in Males than in Females}

Recent developments in the field of epigenetics have added yet another mechanism that may determine phenotypic differences and be subject to natural selection. Increasing evidence suggests that some of these features can be transmitted to the next generation and affect evolutionary changes (Bjornsson et al. 2004; Nadeau 2009). Evolution via epigenetic changes is not well understood but may include alterations in DNA methylation, which is directly associated with gene expression patterns and known to be responsive to environmental exposures. DNA methylation is also known to differ between the sexes and can account for sexual dimorphism (Martin et al. 2017) and the male-biased frequencies of disorders. Given the extensive involvement of environmental effects in the development and functioning of the brain, DNA methylation likely plays a role in the development of mental disorders (Castellani et al. 2015).

A recent study of sex-specific DNA methylation rates with a cohort of 72 participants who had experienced environmental chemical exposure (Leung et al. 2018) reported that increased chemical exposure resulted in more frequent DNA methylation changes in males (4 in 16) compared to females (1 in 16), although this difference was not significant. Moreover, the rate of DNA methylation in males was over a thousand times the rate in females. The study found that $15 \%$ of male-specific $\mathrm{CpG}$ sites were enriched in the cytobands of the $\mathrm{X}$ chromosome that have been associated with neurological disorders. The researchers argued that 
sexually dimorphic responses to environmental exposures may contribute to the increased frequencies of some disorders, including brain disorders, in males compared to females.

\section{De novo Neurodevelopmental Mutations Involved in the Mosaic Brain may Occur more Frequently in Males than Females}

The genome varies not only across individuals but also from cell to cell, making every individual a unique mosaic (Freed et al. 2014). Although mosaicism is not uncommon in mammals, it occurs much more extensively in the mammalian brain than in other organs. Mosaicism occurs due to de novo neurodevelopmental somatic mutations, which result in every human brain's representing a unique combination of genomic variations. The impact of this phenomenon is directly realized in the resulting individual. Mutation rates have been shown to vary widely in somatic tissues, from 8 times in the brain to 122 times in skin cells (Tomasetti et al. 2013; Lodato et al. 2015; Martincorena et al. 2015; Lynch 2016) with an average of 50 -fold inflation. This means that a somatic cell will contain approximately $5000(100 \times 50)$ de novo mutations. Even the eightfold inflation in the brain will produce 800 new mutations per cell. Since all cells within a tissue will not have the same set of mutations, many genes within a tissue will have been mutated, and this number will be larger in the male brain than in the female brain. Some of these mutations may cause and contribute to a variety of neurodevelopmental disorders, including autism, that have been linked to de novo mutations (Ronemus et al. 2014; Richter et al. 2019; Uddin et al. 2018). Additionally, these mutations can affect even healthy individuals, causing variable manifestations including variable thresholds for responses to external exposures.

\section{Clinical Significance}

One might ask whether clinicians and physicians need to know about evolution. The answer is yes. The cells in our bodies have a long evolutionary memory, and if clinicians are to understand the biology of a disease, they must also be aware of evolutionary principles in general and how they impact health related to sex and gender. Physicians often ask patients about their parents and siblings, whether they are living and, if not, how they died. This information provides the physician with a general biological prognosis of a family's health. A surgeon at the operating table may need to be aware of varying dose responses to drugs such as anesthesia and blood thinners in different ethnic populations. The number of situations that involve relevant genetic contributions will continue to increase with advances in molecular insights and precision medication. Cancer clinicians are becoming increasingly interested in understanding mutation-selection clonal dynamics associated with tumor growth, which may facilitate individualized medicine. The medical establishment is becoming increasingly aware of the importance of genetic differences and of sex and gender when assessing health and disease. Therefore, all health researchers must be aware of population diversity, unique individuality, drug complexity and the possibility of gene-drug interactions. As we continue to learn about the genome and move towards precision medicine, physicians and clinicians will need to know about not only the contributions of genetics but also the evolutionary history of these changes. H. J. Muller (1950) best expressed the importance of understanding the contributions of genetics and evolution to human health in the context of high rates of mutations and human fitness, although his comments are equally applicable to sex-biased diseases and mental health:

Only after the opposition [of the groups with vested interest] has become sufficiently weakened to allow the conception of evolution, including that of its genetic mechanism, to become as much a cornerstone of elementary education as the rotundity of the earth, and after the processes and consequences of genetic change throughout the ages have been vividly visualized and dramatized for people in general from their early years on through their later development, can we expect the arguments, calculations and recommendations of geneticists to take on sufficiently concrete meaning for the average man, the medical man, and the man in public life, so as to influence them adequately in their conduct of practical matters. To work for this modernization of educational policy and methods, with a view to reshaping the average man's view of his place in nature, is, therefore, one of the first duties of those who appreciate the significance of genetics in human affairs.

While much has changed in genetics since Muller made those remarks, his remarks still stand with regard to the role of evolution in human health and disease. Origins and patterns of Mendelian diseases have benefited from the principles of population genetics evolution, and many genetic details are being filled in by recent advances in genomic technologies, including single-cell genomics (Macaulay and Voet 2014). We are still far from harnessing the insights of evolution in the origin of sex-biased diseases and precision medicine (Singh and Gupta 2020). Significant sex differences are becoming the focus of attention for many complex diseases. A sex-specific focus on male and male-driven evolutionary causes offers a novel approach to understanding sex-biased complex diseases. Specifically, we argue that autism research would benefit from sex-specific evolutionary approaches. 


\section{Conclusions}

With notable exceptions, such as the "thrifty gene" hypothesis of diabetes (Neel 1962) and the evolution of the complex immune system in response to pathogens, the effects of evolution on human health have been relatively ignored, partly due to the uniqueness of each individual and partly due to the immediacy of the problems facing the clinician. In medicine, as in all functional biology, the why is often more important than the how; however, the field has slowly begun to appreciate that the body has a history and, as the physicist Max Delbruck (1949) remarked, "any living cell carries with it the experiences of a billion years of experimentation by its ancestors."

Although the molecular mechanisms that underlie mental disorders and/or conditions such as autism may be associated with individual risk factors or developmental anomalies, sex-mediated differences in disease prevalence may be associated with the evolutionary history of the sexes. Role of evolution in sex differences is increasingly being appreciated (Morrow 2015; Klein and Flanagan 2016, Fink and Klein 2018). We provide an overarching Sexual Selection-Sex Hormone theory to explain male-biased prevalence of diseases and mental disorders, and higher female immunity. We propose that the male-biased prevalence of mental disorders such as autism may be caused by the joint effects of three processes: (1) increased male vulnerability due to the negative pleiotropic effects of male-driven sexual selection and evolution, causing sex-specific differences in gene expression during neurodevelopment; (2) increased rates of male-driven mutations, both germline and somatic, due to male-driven sexual selection and resulting early fitness gains at the cost of later fitness; and (3) increased female immunity due to the development of antagonistic responses to mutations that are beneficial to males but harmful to females, reducing female vulnerability and increasing the thresholds for the development of mental disorders, including autism. The male-driven processes associated with the rapid evolution of the brain may also result in increased neurodevelopmental male susceptibility. Such insights may help identify differential treatment protocols, including the sex-specific dose-response efficacy of drugs. Researchers and clinicians exploring sexual dimorphism associated with diseases and mental disorders should also consider the health consequences of sexual selection and evolution (Mayr 1961).

Acknowledgements We thank Steve Scherer, Meng-Chuan Lai, Donal Hickey and Rob Kulathinal for their valuable comments on various versions of this manuscript, and Aditi Thakur, Queenie Wong, and Divya Purohith for technical help with references, graphs, and tables. Funding was provided by NSERC (RSS, KKS, and SMS) and CIHR (KKS and SMS).
Authors' Contribution RSS conceived the idea, prepared the framework on evolutionary biology in relation to sex differences, prepared the hypothesis, discussed, and co-wrote the article in collaboration with the co-authors. KKS provided literature on autism and sex differences in disease and health and helped write the paper. SMS provided literature on epigenetics and epimutations and helped write the paper.

Funding Funding for this manuscript was provided by NSERC (RSS, KKS, and SMS) and CIHR (KKS and SMS).

\section{Compliance with Ethical Standards}

Conflict of interest Authors declare that they have no competing interests.

Open Access This article is licensed under a Creative Commons Attribution 4.0 International License, which permits use, sharing, adaptation, distribution and reproduction in any medium or format, as long as you give appropriate credit to the original author(s) and the source, provide a link to the Creative Commons licence, and indicate if changes were made. The images or other third party material in this article are included in the article's Creative Commons licence, unless indicated otherwise in a credit line to the material. If material is not included in the article's Creative Commons licence and your intended use is not permitted by statutory regulation or exceeds the permitted use, you will need to obtain permission directly from the copyright holder. To view a copy of this licence, visit http://creativecommons.org/licenses/by/4.0/.

\section{References}

Abel KM, Drake R, Goldstein JM (2010) Sex differences in schizophrenia. Int Rev Psychiatry 22:417-428

Albert PR (2015) Why is depression more prevalent in women? J Psychiatry Neurosci 40(4):219-221. https://doi.org/10.1503/ jpn. 150205

Albrektsen G, Heuch I, Løchen ML, Thelle DS, Wilsgaard T, Njølstad I, Bønaa KH (2016) Lifelong Gender Gap in Risk of Incident Myocardial Infarction: The Troms $\varnothing$ Study. JAMA Intern Med 176(11):1673-1679. https://doi.org/10.1001/jamaintern med.2016.5451

Andersen SL, Teicher MH (2008) Stress, sensitive periods, and maturational events in adolescent depression. Trends Neurosci 31(4):183-191. https://doi.org/10.1016/j.tins.2008.01.004

Anderson M (1994) Sexual Selection. Princeton University Press, Princeton

Arnold AP (2017) A general theory of sexual differentiation. J Neurosci Res 95(1-2):291-300. https://doi.org/10.1002/jnr.23884

Arnqvist G, Rowe L (2005) Sexual conflict. Princeton University Press, Princeton

Artero-Morales M, González-Rodríguez S, Ferrer-Montiel A (2018) TRP Channels as Potential Targets for Sex-Related Differences in Migraine Pain. Front Mol Biosci 5:73. https://doi.org/10.3389/ fmolb.2018.00073

Assis R, Zhou Q, Bachtrog D (2012) Sex-biased transcriptome evolution in Drosophila. Genome Biol Evol 4(11):1189-1200. https ://doi.org/10.1093/gbe/evs093

Bale TL (2009) Neuroendocrine and immune influences on the CNS: it's a matter of sex. Neuron 64(1):13-16. https://doi. org/10.1016/j.neuron.2009.09.036

Baron-Cohen S (2002) The extreme male brain theory of autism. Trends Cogn Sci 6(6):248-254. https://doi.org/10.1016/s1364 $-6613(02) 01904-6$ 
Baron-Cohen S, Tsompanidis A, Auyeung B, Nørgaard-Pedersen B, Hougaard DM, Abdallah M, Cohen A, Pohl A (2020) Foetal Oestrogens and Autism Mol Psychiatry 25(11):2970-2978. https ://doi.org/10.1038/s41380-019-0454-9

Bateman AJ (1948) Intra-sexual selection in Drosophila. Heredity 2(Pt. 3):349-368. https://doi.org/10.1038/hdy.1948.21

Beaudet AL (2017) Brain carnitine deficiency causes nonsyndromic autism with an extreme male bias A hypothesis BioEssays news and reviews in molecular. Cell Dev Biology. https://doi. org/10.1002/bies.201700012

Bedhomme S, Prasad NG, Jiang PP, Chippindale AK (2008) Reproductive behaviour evolves rapidly when intralocus sexual conflict is removed. PLoS ONE 3(5):e2187. https://doi.org/10.1371/journ al.pone.0002187

Begeer S, Mandell D, Wijnker-Holmes B, Venderbosch S, Rem D, Stekelenburg F, Koot HM (2013) Sex differences in the timing of identification among children and adults with autism spectrum disorders. J Autism Dev Disord 43(5):1151-1156. https://doi. org/10.1007/s10803-012-1656-z

Besenbacher S, Liu S, Izarzugaza JM, Grove J, Belling K, Bork-Jensen J, Huang S, Als TD, Li S, Yadav R et al (2015) Novel variation and de novo mutation rates in population-wide de novo assembled Danish trios. Nat Commun 6:5969. https://doi.org/10.1038/ ncom

Bjornsson HT, Fallin MD, Feinberg AP (2004) An integrated epigenetic and genetic approach to common human disease. Trends Genet 20:350-358. https://doi.org/10.1016/j.tig.2004.06.009

Bourc'his D, Bestor TH (2006) Origins of extreme sexual dimorphism in genomic imprinting. Cytogenet Genome Res 113(1-4):36-40. https://doi.org/10.1159/000090813

Brummelte S, Galea LA (2016) Postpartum depression: Etiology, treatment and consequences for maternal care. Horm Behav 77:153166. https://doi.org/10.1016/j.yhbeh.2015.08.008

Carlson KM, Bracamontes J, Jackson CE, Clark R, Lacroix A, Wells SA, Goodfellow PJ (1994) Parent-of-origin effects in multiple endocrine neoplasia type 2B. Am J Hum Genet 55(6):1076-1082

Castellani CA, Laufer BI, Melka MG, Diehl EJ, O’Reilly RL, Singh SM (2015) DNA methylation differences in monozygotic twin pairs discordant for schizophrenia identifies psychosis related genes and networks. BMC Med Genomics 8:17. https://doi. org/10.1186/s12920-015-0093-1

Cauvet É, Van't Westeinde A, Toro R, Kuja-Halkola R, Neufeld J, Mevel K, Bölte S (2019) Sex Differences Along the Autism Continuum A Twin Study of Brain Structur (New York, N.Y. 1191). Cereb Cortex 29(3):1342-1350. https://doi.org/10.1093/ cercor/bhy303

Chakrabarti S, Fombonne E (2001) Pervasive developmental disorders in preschool children. JAMA 285(24):3093-3099. https:// doi.org/10.1001/jama.285.24.3093

Chan S, Gomes A, Singh RS (2020) Is menopause still evolving? Evidence from a longitudinal study of multiethnic populations and its relevance to women's health. BMC Women's Health 20(1):74. https://doi.org/10.1186/s12905-020-00932-8

Chen H, Li C, Zhou Z, Liang H (2018) Fast-Evolving Human-Specific Neural Enhancers Are Associated with Aging-Related Diseases. Cell systems 6(5):604-611.e4. https://doi.org/10.1016/j. cels.2018.04.002

Chokroborty-Hoque A, Alberry B, Singh SM (2014) Exploring the complexity of intellectual disability in fetal alcohol spectrum disorders. Front Pediatr 2:90. https://doi.org/10.3389/ fped.2014.00090

Consortium C - Cross-Disorder Group of the Psychiatric (2013) Identification of risk loci with shared effects on five major psychiatric disorders: a genome-wide analysis - PubMed - NCBI. The Lancet 381(9875):1371-1379. https://doi.org/10.1016/S0140 $-6736(12) 62129-1$
Constantino JN, Todd RD (2000) Genetic structure of reciprocal social behavior. Am J Psychiatry 157(12):2043-2045. https:// doi.org/10.1176/appi.ajp.157.12.2043

Crow JF (1997) The high spontaneous mutation rate: is it a health risk? Proc Natl Acad Sci USA 94(16):8380-8386. https://doi. org/10.1073/pnas.94.16.8380

CR Darwin 1871 The descent of man, and selection in relation to sex 11 John Murray London

De Rubeis S, He X, Goldberg AP, Poultney CS, Samocha K, Cicek AE et al (2014) Synaptic, transcriptional and chromatin genes disrupted in autism. Nature 515(7526):209-215. https://doi. org/10.1038/nature13772

de Zegher F, Devlieger H, Eeckels R (1999) Fetal growth: boys before girls. Horm Res 51(5):258-259. https://doi.org/10.1159/00002 3382

Delbruck M (1949) A physicist looks at biology. Trans of the Conn Acad Arts Sci 38:173-190

Drost JB, Lee WR (1995) Biological basis of germline mutation: comparisons of spontaneous germline mutation rates among drosophila, mouse, and human. Environ Mol Mutagen 25(Suppl 26):48-64. https://doi.org/10.1002/em.2850250609

Ellegren H (2007) Characteristics causes, and evolutionary consequences of male-biased mutation. Proc Biol Sci 274(1606):110. https://doi.org/10.1098/rspb.2006.3720

Ellegren H, Fridolfsson AK (1997) Male-driven evolution of DNA sequences in birds. Nat Genet 17(2):182-184. https://doi. org/10.1038/ng 1097-182

Feinberg JI, Bakulski KM, Jaffe AE, Tryggvadottir R, Brown SC, Goldman LR, Croen LA, Hertz-Picciotto I, Newschaffer CJ, Fallin MD, Feinberg AP (2015) Paternal sperm DNA methylation associated with early signs of autism risk in an autismenriched cohort. Int J Epidemiol 44(4):1199-1210. https://doi. org/10.1093/ije/dyv028

Feng J, Fouse S, Fan G (2007) Epigenetic Regulation of Neural Gene Expression and Neuronal Function. Pediatr Res 61:58-63. https://doi.org/10.1203/pdr.0b013e3180457635

Fernandez BA, Scherer SW (2017) Syndromic autism spectrum disorders: moving from a clinically defined to a molecularly defined approach. Dialogues Clin Neurosci 19:353-371

Fink AL, Klein SL (2018) The evolution of greater humoral immunity in females than males: implications for vaccine efficacy. Curr Opin Physiol 6:16-20. https://doi.org/10.1016/j.cophy s.2018.03.010

Freed D, Stevens EL, Pevsner J (2014) Somatic mosaicism in the human genome. Genes 5(4):1064-1094. https://doi. org/10.3390/genes5041064

Gaugler T, Klei L, Sanders SJ, Bodea CA, Goldberg AP, Lee AB, Mahajan M, Manaa D, Pawitan Y, Reichert J, Ripke S, Sandin S, Sklar P, Svantesson O, Reichenberg A, Hultman CM, Devlin B, Roeder K, Buxbaum JD (2014) Most genetic risk for autism resides with common variation. Nat Genet 46(8):881-885. https://doi.org/10.1038/ng.3039

Genomes Project Consortium, Abecasis GR, Auton A, Brooks LD, DePristo MA, Durbin RM, Handsaker RE, Kang HM, Marth GT, McVean GA (2012) An integrated map of genetic variation from 1,092 human genomes. Nature 491(7422):56-65. https:// doi.org/10.1038/nature11632

Geschwind DH, Levitt P (2007) Autism spectrum disorders: developmental disconnection syndromes. Curr Opin Neurobiol 17(1):103-111. https://doi.org/10.1016/j.conb.2007.01.009

Giarelli E, Wiggins LD, Rice CE, Levy SE, Kirby RS, Pinto-Martin J, Mandell D (2010) Sex differences in the evaluation and diagnosis of autism spectrum disorders among children. Disability and health journal 3(2):107-116. https://doi.org/10.1016/j. dhjo.2009.07.001 
Gilman SR, Iossifov I, Levy D, Ronemus M, Wigler M, Vitkup D (2011) Rare de novo variants associated with autism implicate a large functional network of genes involved in formation and function of synapses. Neuron 70(5):898-907. https://doi. org/10.1016/j.neuron.2011.05.021

Gockley J, Willsey AJ, Dong S et al (2015) The female protective effect in autism spectrum disorder is not mediated by a single genetic locus. Mol Autism 6:25. https://doi.org/10.1186/s1322 9-015-0014-3

Goldstein JM, Seidman LJ, Goodman JM et al (1998) Are there sex differences in neuropsychological functions among patients with schizophrenia? Am J Psychiatry 155:1358-1364. https:// doi.org/10.1176/ajp.155.10.1358

Guan J, Cai JJ, Ji G et al (2019) Commonality in dysregulated expression of gene sets in cortical brains of individuals with autism, schizophrenia, and bipolar disorder. Transl Psychiatry 9:152. https://doi.org/10.1038/s41398-019-0488-4

Gubbay J, Collignon J, Koopman P, Capel B, Economou A, Münsterberg A, Vivian N, Goodfellow P, Lovell-Badge R (1990) A gene mapping to the sex-determining region of the mouse $\mathrm{Y}$ chromosome is a member of a novel family of embryonically expressed genes. Nature 346(6281):245-250. https://doi. org/10.1038/346245a0

Haerty W, Jagadeeshan S, Kulathinal RJ, Wong A, Ravi Ram K, Sirot LK, Levesque L, Artieri CG, Wolfner MF, Civetta A, Singh RS (2007) Evolution in the fast lane: rapidly evolving sex-related genes in Drosophila. Genetics 177(3):1321-1335. https://doi. org/10.1534/genetics.107.078865

Halladay AK, Bishop S, Constantino JN, Daniels AM, Koenig K, Palmer K, Messinger D, Pelphrey K, Sanders SJ, Singer AT, Taylor JL, Szatmari P (2015) Sex and gender differences in autism spectrum disorder: summarizing evidence gaps and identifying emerging areas of priority. Mol Autism 6:36. https://doi. org/10.1186/s13229-015-0019-y

Hamilton WD (1966) The moulding of senescence by natural selection. J Theor Biol 12(1):12-45. https://doi.org/10.1016/00225193(66)90184-6

Hillman RE, Kanafani N, Takahashi TN, Miles JH (2000) Prevalence of autism in Missouri: changing trends and the effect of a comprehensive state autism project. Mo Med 97(5):159-163

Hu VW, Sarachana T, Sherrard RM et al (2015) Investigation of sex differences in the expression of RORA and its transcriptional targets in the brain as a potential contributor to the sex bias in autism. Mol Autism 6:7. https://doi.org/10.1186/2040-2392-6-7

Hurst LD, Ellegren H (1998) Sex biases in the mutation rate. Trends Genet 14(11):446-452. https://doi.org/10.1016/s0168 -9525(98)01577-7

Iossifov I, O'Roak BJ, Sanders SJ, Ronemus M, Krumm N, Levy D et al (2014) The contribution of de novo coding mutations to autism spectrum disorder. Nature 515(7526):216-221. https:// doi.org/10.1038/nature13908

Jacquemont S, Coe BP, Hersch M, Duyzend MH, Krumm N, Bergmann S, Beckmann JS, Rosenfeld JA, Eichler EE (2014) A higher mutational burden in females supports a "female protective model" in neurodevelopmental disorders. Am J Hum Genet 94(3):415-425. https://doi.org/10.1016/j.ajhg.2014.02.001

Jagadeeshan S, Shah U, Chakrabarti D, Singh R (2015) Female choice or male sex drive? The advantages of male body size in competition and charm during mating in Drosophila melanogaster. PLoS ONE 10(12):e0144672. https://doi.org/10.1371/journ al.pone. 0144672

Jagadeeshan S, Gomes AK, Singh RS (2019) Mate Choice and the Persistence of Maternal Mortality. Reprod Sci 26:450-458. https ://doi.org/10.1177/1933719118812730
Kamitaki N, Sekar A, Handsaker RE et al (2020) Complement genes contribute sex-biased vulnerability in diverse disorders. Nature 582:577-581. https://doi.org/10.1038/s41586-020-2277-x

Kaneko-Ishino T, Kohda T, Ono R, Ishino F (2006) Complementation hypothesis: the necessity of a monoallelic gene expression mechanism in mammalian development. Cytogenet Genome Res 113(1-4):24-30. https://doi.org/10.1159/000090811

Kang HJ, Kawasawa YI, Cheng F, Zhu Y, Xu X, Li M et al (2011) Spatio-temporal transcriptome of the human brain. Nature 478(7370):483-489. https://doi.org/10.1038/nature10523

Karp NA, Mason J, Beaudet AL, Benjamini Y, Bower L, Braun RE, Brown $S$ et al (2017) Prevalence of sexual dimorphism in mammalian phenotypic traits. Nat Commun 8:15475. https://doi. org/10.1038/ncomms 15475

Keightley PD (2012) Rates and fitness consequences of new mutations in humans. Genetics 190(2):295-304. https://doi.org/10.1534/ genetics. 111.134668

Khaitovich P, Enard W, Lachmann M, Pääbo S (2006) Evolution of primate gene expression. Nat Rev Genet 7(9):693-702. https:// doi.org/10.1038/nrg 1940

King MC, Wilson AC (1975) Evolution at two levels in humans and chimpanzees. Science 188(4184):107-116. https://doi. org/10.1126/science. 1090005

Kirkwood TB, Rose MR (1991) Evolution of senescence: late survival sacrificed for reproduction Philosophical transactions of the Royal Society of London. Series B, Biological sciences 332(1262):15-24. https://doi.org/10.1098/rstb.1991.0028

Klei L, Sanders SJ, Murtha MT, Hus V, Lowe JK, Willsey AJ et al (2012) Common genetic variants, acting additively, are a major source of risk for autism. Mol Autism 3(1):9. https://doi. org/10.1186/2040-2392-3-9

Klein SL, Flanagan KL (2016) Sex differences in immune responses. Nat Rev Immunol 16:626-638

Kraemer S (2000) The fragile male. BMJ 321(7276):1609-1612. https ://doi.org/10.1136/bmj.321.7276.1609

Kruger DJ, Nesse RM (2004) Sexual selection and the Male: Female mortality ratio. Evol Psychol 2:66-85. https://doi. org/10.1177/147470490400200112

Krupp DR, Barnard RA, Duffourd Y, Evans SA, Mulqueen RM, Bernier R, Rivière JB, Fombonne E, O'Roak BJ (2017) Exonic Mosaic Mutations Contribute Risk for Autism Spectrum Disorder. Am J Hum Genet 101(3):369-390. https://doi.org/10.1016/j. ajhg.2017.07.016

Ladd-Acosta C (2015) Epigenetic Signatures as Biomarkers of Exposure. Curr Environ Health Rep 2(2):117-125. https://doi. org/10.1007/s40572-015-0051-2

Ladd-Acosta C, Hansen KD, Briem E, Fallin MD, Kaufmann WE, Feinberg AP (2014) Common DNA methylation alterations in multiple brain regions in autism. Mol Psychiatry 19(8):862-871. https://doi.org/10.1038/mp.2013.114

Lai MC, Szatmari P (2020) Sex and gender impacts on the behavioural presentation and recognition of autism. Curr Opin Psychiatry 33(2):117-123. https://doi.org/10.1097/YCO.000000000000057 5

Lai MC, Baron-Cohen S, Buxbaum JD (2015a) Understanding autism in the light of sex/gender. Mol Autism 6:24. https://doi. org/10.1186/s13229-015-0021-4

Lai MC, Lombardo MV, Auyeung B, Chakrabarti B, Baron-Cohen S (2015b) Sex/gender differences and autism: setting the scene for future research. Journal of the J Am Acad Child Adolesc Psychiatry 54(1):11-24. https://doi.org/10.1016/j.jaac.2014.10.003

Lai MC, Lombardo MV, Pasco G, Ruigrok AN, Wheelwright SJ, Sadek SA, Chakrabarti B, MRC AIMS Consortium, Baron-Cohen S (2011) A behavioral comparison of male and female adults with high functioning autism spectrum conditions. PLoS ONE 6(6):e20835. https://doi.org/10.1371/journal.pone.0020835 
Lai MC, Lombardo MV, Suckling J, Ruigrok AN, Chakrabarti B, Ecker C, Deoni SC, Craig MC, Murphy DG, Bullmore ET, MRC AIMS Consortium, Baron-Cohen S (2013) Biological sex affects the neurobiology of autism. Brain a journal of neurology 136(9): 2799-2815. https://doi.org/https://doi.org/10.1093/brain/awt216

Lawniczak MK, Begun DJ (2004) A genome-wide analysis of courting and mating responses in Drosophila melanogaster females. Genome 47(5):900-910. https://doi.org/10.1139/g04-050

Lemos B, Branco AT, Hartl DL (2010) Epigenetic effects of polymorphic $\mathrm{Y}$ chromosomes modulate chromatin components, immune response, and sexual conflict. Proc Natl Acad Sci USA. https:// doi.org/10.1073/pnas.1010383107

Leung YK, Ouyang B, Niu L, Xie C, Ying J, Medvedovic M, Chen A, Weihe P, Valvi D, Grandjean P, Ho SM (2018) Identification of sex-specific DNA methylation changes driven by specific chemicals in cord blood in a Faroese birth cohort. Epigenetics 13(3):290-300. https://doi.org/10.1080/15592294.2018.1445901

Li R, Ma X, Wang G, Yang J, Wang C (2017) Why sex differences in schizophrenia? J Transl Neurosci (Beijing) 1(1):37-42

Li CH, Haider S, Shiah Y-J, Thai K, Boutros PC (2018) Sex Differences in Cancer Driver Genes and Biomarkers. Cancer Res 78(19):5527-5537. https://doi.org/10.1158/0008-5472. CAN-18-0362

Lim ET, Uddin M, De Rubeis S, Chan Y, Kamumbu AS, Zhang X et al (2017) Rates, distribution and implications of postzygotic mosaic mutations in autism spectrum disorder. Nat Neurosci 20(9):1217-1224. https://doi.org/10.1038/nn.4598

Lodato MA, Woodworth MB, Lee S, Evrony GD, Mehta BK, Karger A, Lee S, Chittenden TW, D'Gama AM, Cai X, Luquette LJ, Lee E, Park PJ, Walsh CA (2015) Somatic mutation in single human neurons tracks developmental and transcriptional history. Science 350(6256):94-98. https://doi.org/10.1126/science.aab1785

Loke YJ, Hannan AJ, Craig JM (2015) The Role of Epigenetic Change in Autism Spectrum Disorders. Front Neurol 6:107. https://doi. org/10.3389/fneur.2015.00107

Loomes R, Hull L, Mandy W (2017) What Is the Male-to-Female Ratio in Autism Spectrum Disorder? A Systematic Review and MetaAnalysis. J Am Acad Child Adolesc Psychiatry 56(6):466-474. https://doi.org/10.1016/j.jaac.2017.03.013

Lopes-Ramos CM, Quackenbush J, DeMeo DL (2020) Genome-Wide Sex and Gender Differences in Cancer. Front Oncol 10:597788. https://doi.org/10.3389/fonc.2020.597788

Lynch M (2016) Mutation and Human Exceptionalism: Our Future Genetic Load. Genetics 202:869-875. https://doi.org/10.1534/ genetics.115.180471

Macaulay IC, Voet T (2014) Single cell genomics: advances and future perspectives. PLoS Genet 10(1):e1004126. https://doi. org/10.1371/journal.pgen.1004126

Markow TA (2002) Perspective: female remating, operational sex ratio, and the arena of sexual selection in Drosophila species. Evolution 56(9):1725-1734. https://doi.org/10.1111/j.0014-3820.2002. tb00186.x

Marshall CR, Noor A, Vincent JB, Lionel AC, Feuk L, Skaug J et al (2008) Structural variation of chromosomes in autism spectrum disorder. Am J Hum Genet 82(2):477-488. https://doi. org/10.1016/j.ajhg.2007.12.009

Martin E, Smeester L, Bommarito PA, Grace MR, Boggess K, Kuban K, Karagas MR, Marsit CJ, O’Shea TM, Fry RC (2017) Sexual epigenetic dimorphism in the human placenta: implications for susceptibility during the prenatal period. Epigenomics 9(3):267278. https://doi.org/10.2217/epi-2016-0132

Martincorena I, Roshan A, Gerstung M, Ellis P, Van Loo P, McLaren S, Wedge DC, Fullam A, Alexandrov LB, Tubio JM, Stebbings L, Menzies A, Widaa S, Stratton MR, Jones PH, Campbell PJ (2015) Tumor evolution High burden and pervasive positive selection of somatic mutations in normal human skin. Science 348(6237):880-886. https://doi.org/10.1126/science.aaa6806

Mayr E (1961) Cause and effect in biology. Science 134(3489):15011506. https://doi.org/10.1126/science.134.3489.1501

Meiklejohn CD, Parsch J, Ranz JM, Hartl DL (2003) Rapid evolution of male-biased gene expression in Drosophila. Proc Natl Acad Sci USA 100(17):9894-9899. https://doi.org/10.1073/ pnas. 1630690100

Miles JH (2011) Autism spectrum disorders-a genetics review. Genetics in medicine: official journal of the American College of Medical Genetics 13(4):278-294. https://doi.org/10.1097/GIM.0b013 e3181ff67ba

Miles JH, Hillman RE (2000) Value of a clinical morphology examination in autism. Am J Med Genet 91(4):245-253

Miles JH, Takahashi TN, Bagby S, Sahota PK, Vaslow DF, Wang CH, Hillman RE, Farmer JE (2005) Essential versus complex autism: definition of fundamental prognostic subtypes. Am J Med Genet Part A 135(2):171-180. https://doi.org/10.1002/ajmg.a.30590

Milholland B, Dong X, Zhang L, Hao X, Suh Y, Vijg J (2017) Differences between germline and somatic mutation rates in humans and mice. Nat Commun 8:15183. https://doi.org/10.1038/ncomm s15183

Miyata T, Hayashida H, Kuma K, Mitsuyasu K, Yasunaga T (1987) Male-driven molecular evolution: a model and nucleotide sequence analysis. Cold Spring Harb Symp Quant Biol 52:863867. https://doi.org/10.1101/sqb.1987.052.01.094

Moloney DM, Slaney SF, Oldridge M, Wall SA, Sahlin P, Stenman G, Wilkie AO (1996) Exclusive paternal origin of new mutations in Apert syndrome. Nat Genet 13(1):48-53. https://doi.org/10.1038/ ng0596-48

Morrow EH (2015) The evolution of sex differences in disease. Biol Sex Differ 6:5. https://doi.org/10.1186/s13293-015-0023-0

Morton RA, Stone JR, Singh RS (2013) Mate choice and the origin of menopause. PLoS Comput Biol 9(6):e1003092. https://doi. org/10.1371/journal.pcbi.1003092

Mottron L, Duret P, Mueller S, Moore RD, Forgeot d'Arc B, Jacquemont S, Xiong L (2015) Sex differences in brain plasticity: a new hypothesis for sex ratio bias in autism. Mol Autism 6:33. https:// doi.org/10.1186/s13229-015-0024-1

Muller HJ (1950) Our load of mutations. Am J Hum Genet 2(2):111-176

Nadeau JH (2009) Transgenerational genetic effects on phenotypic variation and disease risks. Hum Mol Genet 18:R202-R210. https://doi.org/10.1093/hmg/ddp366

Nardone S, Sams DS, Reuveni E, Getselter D, Oron O, Karpuj M, Elliott E (2014) DNA methylation analysis of the autistic brain reveals multiple dysregulated biological pathways. Transl Psychiatry 4(9):e433. https://doi.org/10.1038/tp.2014.70

Navara KJ (2014) Low Gestational Weight Gain Skews Human Sex Ratios towards Females. PLoS ONE 9(12):e114304. https://doi. org/10.1371/journal.pone.0114304

Neale BM, Kou Y, Liu L, Ma'ayan A, Samocha KE, Sabo A et al (2012) Patterns and rates of exonic de novo mutations in autism spectrum disorders. Nature 485(7397):242-245. https://doi. org/10.1038/nature11011

Neel JV (1962) Diabetes mellitus: a "thrifty" genotype rendered detrimental by "progress"? Am J Hum Genet 14(4):353-362

O’Roak BJ, Deriziotis P, Lee C, Vives L, Schwartz JJ, Girirajan S, Karakoc E, Mackenzie AP, Ng SB, Baker C, Rieder MJ, Nickerson DA, Bernier R, Fisher SE, Shendure J, Eichler EE (2011) Exome sequencing in sporadic autism spectrum disorders identifies severe de novo mutations. Nat Genet 43(6):585-589. https:// doi.org/10.1038/ng.835

O'Roak BJ, Vives L, Girirajan S, Karakoc E, Krumm N, Coe BP et al (2012) Sporadic autism exomes reveal a highly interconnected 
protein network of de novo mutations. Nature 485(7397):246250. https://doi.org/10.1038/nature10989

Parisi M, Nuttall R, Edwards P, Minor J, Naiman D, Lü J, Doctolero M, Vainer M, Chan C, Malley J, Eastman S, Oliver B (2004) A survey of ovary-, testis-, and soma-biased gene expression in Drosophila melanogaster adults. Genome Biol 5(6):R40. https ://doi.org/10.1186/gb-2004-5-6-r40

Parker GA, Partridge L (1998) Sexual conflict and speciation Philios Trans R Soc London. Series B Biological sciences 353(1366):261-274. https://doi.org/10.1098/rstb.1998.0208

Parsch J, Ellegren H (2013) The evolutionary causes and consequences of sex-biased gene expression. Nat Rev Genet 14:83-87

Pinto D, Pagnamenta AT, Klei L, Anney R, Merico D, Regan R et al (2010) Functional impact of global rare copy number variation in autism spectrum disorders. Nature 466(7304):368-372. https ://doi.org/10.1038/nature09146

Pinto D, Delaby E, Merico D, Barbosa M, Merikangas A, Klei L et al (2014) Convergence of genes and cellular pathways dysregulated in autism spectrum disorders. Am J Hum Genet 94(5):677-694. https://doi.org/10.1016/j.ajhg.2014.03.018

Pröschel M, Zhang Z, Parsch J (2006) Widespread adaptive evolution of Drosophila genes with sex-biased expression. Genetics 174(2):893-900. https://doi.org/10.1534/genetics.106.058008

PsychENCODE Consortium, Akbarian S, Liu C, Knowles JA, Vaccarino FM, Farnham PJ, Crawford GE, Jaffe AE et al (2015) The PsychENCODE project. Nat Neurosci 18(12), 1707-1712. https://doi.org/https://doi.org/10.1038/nn.4156

Ranz JM, Castillo-Davis CI, Meiklejohn CD, Hartl DL (2003) Sexdependent gene expression and evolution of the Drosophila transcriptome. Science (New York, N.Y.) 300(5626), 1742-1745. https://doi.org/https://doi.org/10.1126/science.1085881

Rawlik K, Canela-Xandri O (2016) Tenesa A (2016) Evidence for sex-specific genetic architectures across a spectrum of human complex traits. Genome Biol 17:166. https://doi.org/10.1186/ s13059-016-1025-x

Raymond CS, Shamu CE, Shen MM, Seifert KJ, Hirsch B, Hodgkin J, Zarkower D (1998) Evidence for evolutionary conservation of sex-determining genes. Nature 391(6668):691-695. https://doi. org/10.1038/35618

Reik W, Walter J (2001) Genomic imprinting: parental influence on the genome. Nat Rev Genet 2(1):21-32. https://doi. org/10.1038/35047554

Reuter MS, Walker S, Thiruvahindrapuram B, Whitney J, Cohn I, Sondheimer N et al (2018) The Personal Genome Project Canada: findings from whole genome sequences of the inaugural 56 participants. CMAJ 190(5):E126-E136. https://doi.org/10.1503/ cmaj.171151

Rice WR (1994) Degeneration of a nonrecombining chromosome. Science (New York, N.Y.) 263(5144), 230-232. https://doi.org/https ://doi.org/10.1126/science.8284674

Rice WR, Chippindale AK (2001) Intersexual ontogenetic conflict. J Evol Biol 14:685-693. https://doi.org/10.104 6/j.1420-9101.2001.00319.x

Richter M, Murtaza N, Scharrenberg R, White SH, Johanns O, Walker $\mathrm{S}$ et al (2019) Altered TAOK2 activity causes autism-related neurodevelopmental and cognitive abnormalities through RhoA signaling. Mol psychiatry 24(9):1329-1350. https://doi. org/10.1038/s41380-018-0025-5

Rigby N, Kulathinal RJ (2015) Genetic Architecture of Sexual Dimorphism in Humans. J Cell Physiol 230(10):2304-2310. https://doi. org/10.1002/jcp.24979

Robinson EB, Lichtenstein P, Anckarsäter H, Happé F, Ronald A (2013) Examining and interpreting the female protective effect against autistic behavior. Proc Natl Acad Sci USA 110(13):52585262. https://doi.org/10.1073/pnas.1211070110
Robinson EB, Neale BM, Hyman SE (2015) Genetic research in autism spectrum disorders. Curr Opin Pediatr 27(6):685-691. https:// doi.org/10.1097/MOP.0000000000000278

Ronemus M, Iossifov I, Levy D, Wigler M (2014) The role of de novo mutations in the genetics of autism spectrum disorders. Nat Rev Genet 15(2):133-141. https://doi.org/10.1038/nrg3585

Samocha KE, Robinson EB, Sanders SJ, Stevens C, Sabo A, McGrath LM et al (2014) A framework for the interpretation of de novo mutation in human disease. Nat Genet 46(9):944-950. https:// doi.org/10.1038/ng.3050

Sanders SJ, Murtha MT, Gupta AR, Murdoch JD, Raubeson MJ, Willsey AJ et al (2012) De novo mutations revealed by wholeexome sequencing are strongly associated with autism. Nature 485(7397):237-241. https://doi.org/10.1038/nature10945

Sebat J, Lakshmi B, Malhotra D, Troge J, Lese-Martin C, Walsh T et al (2007) Strong association of de novo copy number mutations with autism. Science 316(5823):445-449. https://doi. org/10.1126/science. 1138659

Shattuck PT, Durkin M, Maenner M, Newschaffer C, Mandell DS, Wiggins L et al (2009) Timing of identification among children with an autism spectrum disorder: findings from a populationbased surveillance study. J Am Acad Child Adolesc Psychiatry 48(5):474-483. https://doi.org/10.1097/CHI.0b013e31819b3848

Shi L, Zhang Z, Su B (2016) Sex Biased Gene Expression Profiling of Human Brains at Major Developmental Stages. Sci Rep 6:21181. https://doi.org/10.1038/srep21181

Sinclair AH, Berta P, Palmer MS, Hawkins JR, Griffiths BL, Smith MJ, Foster JW, Frischauf AM, Lovell-Badge R, Goodfellow PN (1990) A gene from the human sex-determining region encodes a protein with homology to a conserved DNA-binding motif. Nature 346(6281):240-244. https://doi.org/10.1038/346240a0

Singh RS, Gupta BG (2020) Genes and genomes and unnecessary complexity in precision medicine. Genomic Medicine 5(1):21. https://doi.org/10.1038/s41525-020-0128-1

Singh RS, Jagadeeshan S (2018) Charles Darwin: Theory of Sexual Selection. Springer International Publishing AG, part of Springer Nature 2018 T. K. Shackelford, V. A. Weekes-Shackelford (eds.), Encyclopedia of evolutionary psychological sciences. https://doi.org/https://doi.org/10.1007/978-3-319-16999 $-6 \_1396-1$

Singh RS, Kulathinal RJ (2005) Male sex drive and the masculinization of the genome BioEssays : news and reviews in molecular. Cell Dev Biol 27(5):518-525. https://doi.org/10.1002/bies.20212

Singh SM, Castellani CA, Hill KA (2020) Postzygotic Somatic Mutations in the Human Brain Expand the Threshold-Liability Model of Schizophrenia. Psychiatry, Front. https://doi.org/10.3389/fpsyt .2020 .587162

Skuse DH (2005) X-linked genes and mental functioning. Hum Mol Genet 14 Spec No 1, R27-R32. https://doi.org/https://doi. org $/ 10.1093 / \mathrm{hmg} / \mathrm{ddi} 112$

Slavich GM, Sacher J (2019) Stress, sex hormones, inflammation, and major depressive disorder: Extending Social Signal Transduction Theory of Depression to account for sex differences in mood disorders. Psychopharmacology 236(10):3063-3079. https://doi. org/10.1007/s00213-019-05326-9

Sofroniew NJ (2017) Q\&A: The brain under a mesoscope: the forest and the trees. BMC Biol 15(1):82. https://doi.org/10.1186/s1291 5-017-0426-y

Sousa A, Meyer KA, Santpere G, Gulden FO, Sestan N (2017) Evolution of the Human Nervous System Function, Structure, and Development. Cell 170(2):226-247. https://doi.org/10.1016/j. cell.2017.06.036

Stanley CE, Kulathinal RJ (2016) Neurogenomics and the role of a large mutational target on rapid behavioral change. Biol Direct 11:60. https://doi.org/10.1186/s13062-016-0162-1 
Takahashi M, Singh RS, Stone J (2017) A Theory for the Origin of Human Menopause. Front Genet 7:222. https://doi.org/10.3389/ fgene.2016.00222

Tartaglia M, Zampino G, Gelb BD (2010) Noonan syndrome: clinical aspects and molecular pathogenesis. Mol Syndromol 1(1):2-26. https://doi.org/10.1159/000276766

Tomasetti C, Vogelstein B, Parmigiani G (2013) Half or more of the somatic mutations in cancers of self-renewing tissues originate prior to tumor initiation. Proc Natl Acad Sci USA 110(6):19992004. https://doi.org/10.1073/pnas.1221068110

Torgerson DG, Kulathinal RJ, Singh RS (2002) Mammalian sperm proteins are rapidly evolving: evidence of positive selection in functionally diverse genes. Mol Biol Evol 19(11):1973-1980. https://doi.org/10.1093/oxfordjournals.molbev.a004021

Torres EB, Isenhower RW, Yanovich P, Rehrig G, Stigler K, Nurnberger JJV (2013) Strategies to develop putative biomarkers to characterize the female phenotype with autism spectrum disorders. J Neurophysiol 110(7):1646-1662. https://doi.org/10.1152/ jn.00059.2013

Trabzuni D, Ramasamy A, Imran S, Walker R, Smith C, Weale ME, Hardy J, Ryten M, North American Brain Expression Consortium (2013) Widespread sex differences in gene expression and splicing in the adult human brain. Nat Comm 4:2771. https://doi. org/10.1038/ncomms3771

Tremblay MW, Jiang YH (2019) DNA methylation and susceptibility to autism spectrum disorder. Annu Rev Med 70:151-166. https ://doi.org/10.1146/annurev-med-120417-091431

Trost B, Engchuan W, Nguyen CM, Thiruvahindrapuram B, Dolzhenko E et al (2020) Genome-wide detection of tandem DNA repeats that are expanded in autism. Nature 585:80-86

Tuljapurkar SD, Puleston CO, Gurven MD (2007) Why men matter: mating patterns drive evolution of human lifespan. PLoS ONE 2(8):e785. https://doi.org/10.1371/journal.pone.0000785

Uddin M, Unda BK, Kwan V, Holzapfel NT, White SH, Chalil L et al (2018) OTUD7A Regulates Neurodevelopmental Phenotypes in the 15q13.3 Microdeletion Syndrome. Am J Hum Genet 102(2), 278-295. https://doi.org/https://doi.org/10.1016/j. ajhg.2018.01.006

United Nations Population Facts (2016) Changing patterns of marriage and unions across the world. Population Facts. December 2016.

Van Vollenhoven RF (2009) Sex differences in rheumatoid arthritis: more than meets the eye. BMC Med 7:12. https://doi. org/10.1186/1741-7015-7-12
Werling DM (2016) The role of sex-differential biology in risk for autism spectrum disorder. Biol Sex Differ 7:58. https://doi. org/10.1186/s13293-016-0112-8

Werling DM, Geschwind DH (2015) Recurrence rates provide evidence for sex-differential, familial genetic liability for autism spectrum disorders in multiplex families and twins. Mol Autism 6:27. https ://doi.org/10.1186/s13229-015-0004-5

Whitlock MC, Agrawal AF (2009) Purging the genome with sexual selection: reducing mutation load through selection on males. Evolution 63(3):569-582. https://doi.org/10.111 1/j.1558-5646.2008.00558.x

Wilfert AB, Sulovari A, Turner TN, Coe BP, Eichler EE (2017) Recurrent de novo mutations in neurodevelopmental disorders: properties and clinical implications. Genome Med 9(1):101. https://doi. org/10.1186/s13073-017-0498-x

Williams GC (1957) Pleiotropy, natural selection, and the evolution of senescence. Evolution

Wilson Sayres MA, Makova KD (2011) Genome analyses substantiate male mutation bias in many species. BioEssays : news and reviews in molecular, Cell Dev Biol 33(12):938-945. https://doi. org/10.1002/bies.201100091

Wolfner MF, Harada HA, Bertram MJ, Stelick TJ, Kraus KW, Kalb JM, Lung YO, Neubaum DM, Park M, Tram U (1997) New genes for male accessory gland proteins in Drosophila melanogaster. Insect Biochem Molec 27(10):825-834. https://doi.org/10.1016/s0965 -1748(97)00056-8

Woodbury-Smith M, Paterson AD, O'Connor I, Zarrei M, Yuen R, Howe JL, Thompson A, Parlier M, Fernandez B, Piven J, Scherer SW, Vieland V, Szatmari P (2018) A genome-wide linkage study of autism spectrum disorder and the broad autism phenotype in extended pedigrees. J Neurodev Disord 10(1):20. https://doi. org/10.1186/s11689-018-9238-9

Xu H, Wang F, Liu Y, Yu Y, Gelernter J, Zhang H (2014) Sex-biased methylome and transcriptome in human prefrontal cortex. Hum Mol Genet 23(5):1260-1270. https://doi.org/10.1093/hmg/ddt51 6

Zhang Z, Hambuch TM, Parsch J (2004) Molecular evolution of sexbiased genes in Drosophila. Mol Biol Evol 21(11):2130-2139. https://doi.org/10.1093/molbev/msh223

Zhang Y, Sturgill D, Parisi M, Kumar S, Oliver B (2007) Constraint and turnover in sex-biased gene expression in the genus Drosophila. Nature 450(7167):233-237. https://doi.org/10.1038/natur e06323 